\title{
Charles Gagnon's Use of SX-70 and Minox Cameras in the Context of his Photographic Work
}

by

Samuel Bernier-Cormier, BFA, OCAD University, 2015

A thesis presented to Ryerson University in partial fulfillment of the requirements for the degree of Master of Arts in the program of

Photography Preservation and Collections Management

Toronto, ON, Canada, 2018

(C) Samuel Bernier-Cormier, 2018 


\section{Author's Declaration}

I hereby declare that I am the sole author of this thesis. This is a true copy of the thesis, including any required final revisions, as accepted by my examiners.

I authorize Ryerson University to lend this thesis to other institutions or individuals for the purpose of scholarly research

I further authorize Ryerson University to reproduce this thesis by photocopying or by other means, in total or in part, at the request of other institutions or individuals for the purpose of scholarly research.

I understand that my thesis may be made electronically available to the public. 


\begin{abstract}
Charles Gagnon's Use of SX-70 and Minox Cameras in the Context of his Photographic Work

Samuel Bernier-Cormier, MA, Ryerson University,

Film and Photography Preservation and Collections Management
\end{abstract}

This thesis addresses two groups of photographs by the multi-disciplinary Canadian artist

Charles Gagnon (1934-2003) from the Art Gallery of Ontario's collection. The first are 21 SX-70

type Polaroid colour prints made between 1976 and 1979. The second are 18 small black and

white photographs taken with a Minox camera between 1977 and 1978. This currently represents

the largest collection of these works by Gagnon. This thesis investigates their position and role

within the larger context of the artist's oeuvre. The apparatuses used in the production of these

photographs are very particular and differ from traditional $35 \mathrm{~mm}$ film photography. The traces of

these characteristics emerge in the photographs and illustrate a connection to Gagnon's work in other mediums that is rooted in his philosophical dispositions as an artist. 


\section{AKNOWLDEGMENT}

Thank you to Geoffrey James and Ronald Nasgaard who kindly met with me and shared their knowledge and memories of Charles Gagnon. This thesis would not have been possible without the help of Michiko Gagnon who provided me with incredible insight into her husband's artistic practice and Eames Gagnon with whom I shared a very fruitful conversation about his father's art. Both of them gave me access to material from the Gagnon estate which moved my research forward. Many thanks to Sophie Hackett for introducing me to this amazing body of photographs and providing important editing efforts as my second reader. Finally I would like to thank my advisor Maia Sutnik for her incredible guidance and support throughout my research process. 


\section{Table of Contents}

$\operatorname{ABSTRACT} \ldots \ldots \ldots \ldots \ldots \ldots \ldots \ldots \ldots \ldots \ldots \ldots \ldots \ldots \ldots \ldots \ldots \ldots \ldots \ldots \ldots$ iii

LIST OF ILLUSTRATIONS $\ldots \ldots \ldots \ldots \ldots \ldots \ldots \ldots \ldots \ldots \ldots \ldots \ldots \ldots$

INTRODUCTION $\ldots \ldots \ldots \ldots \ldots \ldots \ldots \ldots \ldots \ldots \ldots \ldots \ldots \ldots \ldots \ldots$

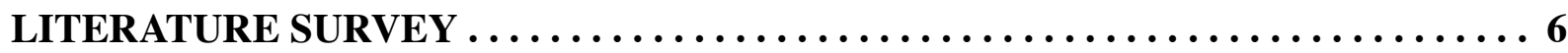

CHAPTER I : The Philosophy of a Multi-Disciplinary Practice . . . . . . . . . . . . . 14

CHAPTER II $:$ Input $/$ Output $\ldots \ldots \ldots \ldots \ldots \ldots \ldots \ldots \ldots \ldots \ldots \ldots \ldots \ldots \ldots \ldots$

CHAPTER III $:$ Landscape, Re-Imagined $\ldots \ldots \ldots \ldots \ldots \ldots \ldots \ldots \ldots \ldots \ldots \ldots \ldots \ldots$

CHAPTER IV : Windows: Creation of a Frame $\ldots \ldots \ldots \ldots \ldots \ldots \ldots \ldots \ldots \ldots$

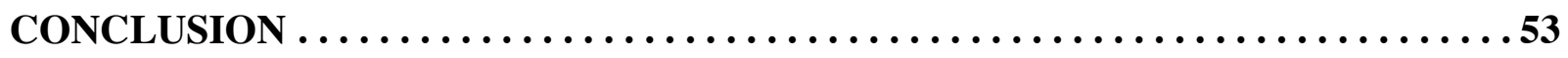

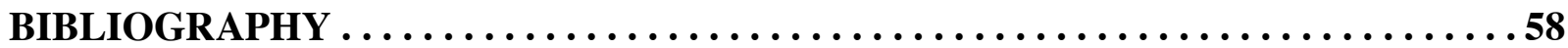




\section{List of Illustrations}

All works are from the Art Gallery of Ontario's collection unless otherwise stated.

Charles Gagnon photographs, Gift of Michiko Gagnon, 2010

Josef Sudek photograph, Anonymous Gift, 2000

Fig. 1 : Charles Gagnon, $M N: X V-34-77,1977$, Gelatin Silver Print, 6.9 x 9.3 cm （p. 5)

Fig. 2 : Charles Gagnon, SX70 (78/393), 1978, Polaroid Instant Print, 10.8 x 8.8 cm (p.5)

Fig. 3 : Charles Gagnon, Poubelle, NYC, 1958, Gelatin Silver Print （p. 16)

Fig. 4 : Charles Gagnon, Vol Nocturne \#1, 1958-59, Oil on Canvas, 25.5 x $20.2 \mathrm{~cm} \mathrm{(p.} \mathrm{16)}$

Fig. 5 : Charles Gagnon, Theatre Marquee with Garbage Bags, 1973, Gelatin Silver Print, $17 \times 25.5 \mathrm{~cm} \quad$ (p. 21)

Fig. 6 : The Minox B model, courtesy of the Ryerson Archives (p. 26)

Fig. 7 : Charles Gagnon, $M N$ : XXIII-30-77, 1977, Gelatin Silver Print, 6.9 x 9.3 cm (p. 27)

Fig. 8 : Polaroid SX-70 model, from author's personal collection $\quad$ (p. 28)

Fig. 9 : Cover of LIFE Magazine, October 27, $1972 \quad$ (p. 29)

Fig. 10 : André Kerész, Glass Blue Birds, 1981, Polaroid Instant Print, 10.8 x 8.8 cm (p. 30)

Fig. 11 : Still from Charles and Ray Eames' promotional film for the Polaroid SX-70, 1972 from Christopher Bonanos's Instant: The Story of Polaroid (p. 32)

Fig. 12 : Charles Gagnon, SX70 (78/210), 1978, Polaroid Instant Print, 10.8 x 8.8 cm (Verso) (p. 32)

Fig. 13 : Lee Friedlander, Staten Island, 1963, 1963, Gelatin Silver Print from Nathan Lyons' Towards a Social Landscape (p. 35)

Fig. 14 : Charles Gagnon, Miroiterie - N.Y., 1969, 1969, Gelatin Silver Print, 17 x 25.5 cm (p. 35) 
Fig. 15 : Charles Gagnon, Autoroute New York, près d'Albany, 1966, 1966, Gelatin Silver Print, 17 x 25.5 cm (p. 36)

Fig. 16 : Garry Winogrand, Los Angeles, 1964, 1964, Gelatin Silver Print from Nathan Lyons' Towards a Social Landscape (p. 36)

Fig. 17 : Cover of Perspective, February 9, 1974 published by La Presse (p. 40)

Fig. 18 : Charles Gagnon, $M N$ : XXVIII-28-77, 1977, Gelatin Silver Print, 6.9 x $9.3 \mathrm{~cm}$ (p. 43)

Fig. 19 : Charles Gagnon, SX70 (77/71), 1977, Polaroid Instant Print, 10.8 x 8.8 cm $\quad$ (p. 43)

Fig. 20 : Charles Gagnon, The Window (Box No.6) (La Fenêtre), 1962, painted wooden box with glass window, mixed-media painting, blind, mirrors and cardboard, $94 \times 49.5 \times 23.8 \mathrm{~cm}$ from the collection of the National Gallery of Canada (p. 45)

Fig. 21 : Josef Sudek, From my Window, 1940, Gelatin Silver Print, 17.2 x $10.3 \mathrm{~cm} \quad$ (p. 47)

Fig. 22 : Charles Gagnon, $M N$ : XXXVI-23-77, 1977, Gelatin Silver Print, 6.9 x $9.3 \mathrm{~cm}$ (p. 47)

Fig. 23 : Charles Gagnon, $M N$ : XLVII-11-78, 1977, Gelatin Silver Print, 6.9 x 9.3 cm (p. 48)

Fig. 24 : Charles Gagnon, Steps (\#2) / Étapes (\#2), 1968, Oil on Canvas, 203.9 x $274.4 \mathrm{~cm}$ (p. 49)

Fig. 25 : Charles Gagnon, SX70 (77/75), 1977, Polaroid Instant Print, 10.8 x 8.8 cm (p. 49)

Fig. 26 : Charles Gagnon, Continuum, 1989, Oil on Canvas, 203.4 x $305 \mathrm{~cm}$ from the Montreal Museum of Fine Arts' catalogue Charles Gagnon (p. 50)

Fig. 27 : Charles Gagnon, $S X 70$ (78/375), 1977, Polaroid Instant Print, 10.8 x 8.8 cm (p. 54)

Fig. 28 : Charles Gagnon, $M N: X X X I I I-2-77,1977$, Gelatin Silver Print, 6.9 x 9.3 cm (p. 54) 


\section{Introduction}

Charles Gagnon was an important and forward-thinking figure in Canadian art, with a multi-disciplinary oeuvre that spans over five decades and deserves close examination. He worked in painting, photography, collage, film, design, and music. Painting and photography, however, stayed the two main practices throughout of his career. While the artist kept a separation between the two, there is a philosophical thread to be drawn across Gagnon's entire work. Most of his photographs were produced using a $35 \mathrm{~mm}$ film camera. However, he began to experiment with other types of apparatuses in the late 1970's. This is an important moment in Gagnon's practice, as it reveals much about the connection between the artist's different mediums. Using a SX-70-type Polaroid and a Minox camera, Gagnon created a body of smaller format works, which illustrate the philosophical backbone of his oeuvre. These small intimate images leave behind the modernist values of the pristine black-and-white photographic print to lay bare Gagnon's artistic impulses. Throughout his career, the artist did not extensively address but has only alluded to the meaning of his wide ranging work. However, looking at these small photographs, it is almost as if we are being let it on a secret and given a rare insight into Gagnon's dispositions as an artist. This thesis will consider the following question: How do Gagnon's SX-70 and Minox photographs provide new insight into the artist's multi-disciplinary practice? Of consequence is Gagnon's philosophical approach to multi-disciplinary art, the technical characteristics of the two camera apparatuses, the subject matter of the photographs as it relates to notions of 'landscape', and finally, the window as a visual motif. To gain a deeper comprehension of the context of Gagnon's photographic work, however, it is at first important to 
address his biography and the existing scholarship that covers his oeuvre, which will be presented as a literature survey.

Gagnon was born in Montreal, Québec, in 1934. He attended the College Stanislas school, where at a young age he was first introduced to painting and photography, which he studied throughout high school. By working at his father's insurance company, Gagnon halted his artistic aspirations. He quickly became dissatisfied with this career direction and started spending time on Stanley Street, where a rich artistic community was flourishing. Jimmey Jones, a gallerist and central figure to this group of artists, owned a studio in the neighbourhood frequently visited by Gagnon and in 1952 he began painting again. The growing cultural sector of Montreal in the early 1950's opened Gagnon's eyes to some exciting opportunities. It is around this time that he became enamoured with Jazz music, a sound that would come to influence his work because of its improvisational qualities. An interest in the Abstract Expressionist movement prompted Gagnon to move to New York City in 1955 to pursue studies at Parsons School of Design. Surrounded by new and innovative influences, he created a large body of paintings and returned to photography, which he had not practiced since his teenage years. ${ }^{1}$ Enriched by the cultural life of New York City and his observations of its urban landscape, Gagnon pushed and developed his artistic concepts.

In 1960 Gagnon returned to Montreal, fully committed to his artistic production and presented his first solo exhibition at the Denise Delrue gallery. He quickly became one of the promising talents in the Québec art scene, working in a style different from most other Montreal

1 Phillip Fry, Charles Gagnon: Une Exposition. 44-45 
painters of the time known as the Plasticiens. Critics appreciated the experimental qualities of the work, which were partly founded in his New York experience..$^{2}$ At this point in his career, Gagnon's painting and photography remained quite separate activities. He mostly photographed while travelling away from Montreal. As one of the first Canadian artists to also practice avantgarde film-making prominently, his film, Le Huitième Jour (The Eighth Day), was presented at Expo '67 in Montreal, in the Christian pavilion, for which he also designed the building. ${ }^{3}$ It is around this time that the artist begins to receive significant attention from Canadian art museums and institutions.

In 1971, he participated in Robert Frank’s Apeiron Workshop in Millerton, New York, where he came in contact with American photographers like Lee Friedlander, who would become a friend and influence. ${ }^{4}$ Photography then became a larger part of Gagnon's oeuvre as he becomes interested in exploring the world using the camera lens. Throughout the 1970s, he explored different types of apparatuses: $35 \mathrm{~mm}$ film format cameras, the SX-70 Polaroid camera and the Minox sub-miniature camera. The paintings and photographs of this period seem much more connected than they had been in the past. In fact, they were exhibited together for the first time in 1978 at the Montreal Museum of Fine Arts. The connection between them is rooted in Gagnon's philosophical impulses as an artist, which embrace a psychic and open-minded approach that engages the viewer rather than relying on any formal definitions. He continued to express himself through his wide range of interests centred around paintings and photographs but

\footnotetext{
${ }^{2}$ Laurent Lamy and Charles Gagnon, L'Art Aujourd'hui, 10:00-10:45

3 Fry. 43

4 Geoffrey James, “On the Work of Charles Gagnon.” 19:16-19:30
} 
also as a teacher of the visual arts both at Concordia University and the University of Ottawa until his death in 2003.

The Art Gallery of Ontario's (AGO) collection of works by Gagnon is mostly comprised of photographs due to a large donation by the artist's widow, Michiko Gagnon, in 2010. This includes the entirety of the works presented in Observations, the photographic retrospective organized by the Musée du Québec in 1998. These 111 prints of Gagnon's 35mm work are dated from 1966 to 1991.5 The AGO's collection also includes 21 of the artist's prints made with the SX-70 Polaroid camera and 18 photographs made with the Minox camera (Figures 1 and 2 are examples of these two types of photographs). While this is only a small portion of these two bodies of work from the 1970's, it currently represents the most extensive collection of these works in an arts institution.

Gagnon acquired a SX-70 type Polaroid camera in 1976 and produced over 500 prints within a few years. All of the colour photographs were shot from the interior of his home, looking out of the house's various windows. The presence of the window is made evident with the inclusion of its frame in each image. This body of colour work can be seen as a circumscribed project within the artist's larger photographic practice.The black and white Minox photographs, made between 1977 and 1978, are much more in line with Gagnon's 35mm work with subject matter anchored in their urban settings. However, they are produced from a much smaller negative measuring merely $9 \mathrm{~mm}$. As a result, the photographs are smaller and grainier than the artist's larger prints. Both groups of photographs are acts of experimentation in

5 These photographs also reside in the collections of the National Gallery of Canada and the Montreal Museum of Fine arts 
expressive photography at a time where the limits of the medium were being stretched, in terms of production, presentation and its place within arts institutions. These two modes of imagemaking are tightly connected to a larger system of production tied to the artist's painting and photography, which embraces the post-modern flexibility of artistic practices rather than any rigid categorization.

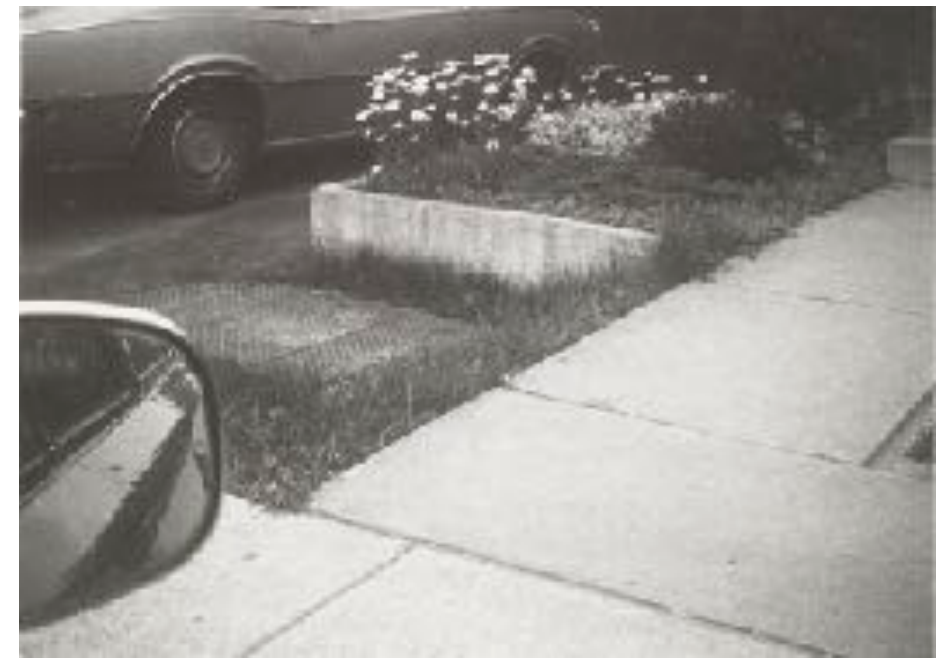

Fig. 1

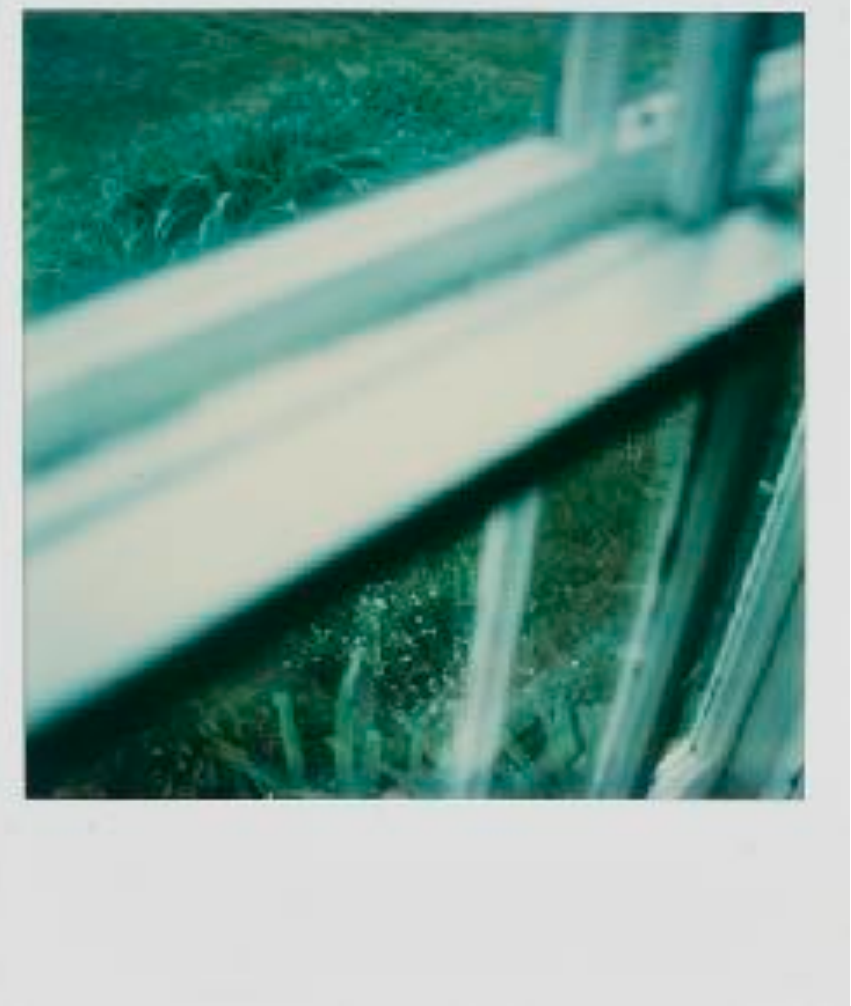

Fig. 2 


\section{Literature Survey}

Before surveying the literature regarding Charles Gagnon's photography specifically, it is important to set up a historical framework. We must understand Gagnon's position within the history of Canadian photography and also be familiar with the socio-political climate of the late 1960's and the 1970's. Photography historian Martha Langford provides much of this base of knowledge in her essay “A Short History of Photography in Canada, 1900-2000” from Visual Arts in Canada: the Twentieth Century. Langford summarizes the development and progression of different photographic approaches in the 20th century in Canada and concentrates on the shifting relationship between documentation and expressive modes of image-making. Langford begins this discussion with a look at photographer Arthur Goss, who was involved in official documentation of urban life in Toronto, as well as creating personal pictorial works for artistic consideration. Significant to the discussion is the blurring of the line between these two aspects of photography, which becomes evident as press photographers begin to be more concerned with issues of aesthetics. Finally, Langford explores the change in mentality, attributed to postmodernist art ideas, which makes such distinctions much harder to make. This last part of the chapter is most relevant to my research as Charles Gagnon's photography is situated somewhere between document and expression. It is part of what Langford refers to as the "social landscape,"'6 a term first used by photographer Nathan Lyons in the catalogue of his 1966 exhibition Towards a Social Landscape. Gagnon's photographs are founded within documentary traditions, but form highly symbolic visual language, which pushes the urban landscape to the edge of abstraction. As indicated in its title, this chapter is a short overview of a complex history.

\footnotetext{
${ }^{6}$ Martha Langford. “A Short History of Photography in Canada, 1900-2000” 295
} 
Langford does, however, cover a large amount of information in her short text. There are many references to artists, processes, and moments, therefore this text also serves as an index for further research on the history of Canadian photography.

While Gagnon mostly practiced in Canada, he was highly influenced by work being made in the United States, both in the field of painting and photography as well as multi-disciplinary experimentation. He formed the foundation for much of his work while living in New York between 1955 and 1960, an influence that would remain present throughout his entire career. Mary K. Statzer's doctoral dissertation “'Photography into Sculpture' : Peter Bunnell, Robert Heinecken and experimental forms of photography circa 1970" provides ample information about the shifts happening in American photography, both in practice and institutionally, during the 1970's. Statzer explains that the show, curated by Peter Bunnell, was the first large American exhibition to emphasize experimental forms of photography. The works were multi-disciplinary in nature as all of the artists utilized three dimensions in their presentation of the medium. The photographs became objects. ${ }^{7}$ This is relevant in thinking about the materiality of Gagnon's Minox and SX-70 prints. While it does not address Gagnon's practice, this text is relevant to this research because it analyses photographic work's relationship to another medium. While Statzer focuses on sculpture, this thesis requires an understanding of the relationship between photography and painting in Gagnon's career. Statzer's thesis does not only represent a similar research approach, it also provides a detailed history of American art photography's development in the 1970's, when the importance of the image over its presentation was being questioned. This is the decade during which Gagnon's photographic work took a dominant role in his artistic

7 Mary K. Statzer "Photography Into Sculpture”. 16 
practice. This text provides important contextual information, with which to frame Gagnon's work within his personal artistic sphere and the development of photographic activities in the United States and Canada.

This connection between Gagnon's two most prominent mediums, photography and painting, is the basis for much of the literature surrounding the works in the AGO's collection. The artist's first major solo exhibition was presented in 1978 at the Musée des Beaux Arts de Montréal. In his catalogue essay "Foundations," the curator Phillip Fry produces one of the first extensive pieces of writing about Gagnon that includes his photography. In this text, Fry summarizes and expands upon the show's four sections, which he calls 'foundations' ${ }^{8}$. These sections form a chronology, from Gagnon's childhood, through his New York City years from 1955 to 1960 and his 1970's work. Throughout the text, Fry categorizes Gagnon's work, justifying the thematic connections made between them, resulting in the photographs being discussed primarily within the framework of Gagnon's painting practice. This allows for a relevant discussion of Gagnon's way of thinking and working in a multi-disciplinary way, which manifests itself as a "non-resolved tension between literal and pictorial characteristics." 9 However, Fry does not engage in an an independent analysis of Gagnon's photographic work. Approximately half of the 156 works in the exhibition were photographs, which in itself shows the importance the medium had taken in the artist's practice by the late 1970's. Some of these works exhibited were the Minox and SX-70 photographs and neither are discussed in the text. While Fry's essay acknowledges Gagnon's photography, it is mostly as a means to speak about

\footnotetext{
8 Fry. 23

9 Ibid. 65
} 
Gagnon's painting practice. This nevertheless makes it a useful text in understanding the influences between the artist's use of different mediums. It also exposes a gap in analysis of his photographs as art objects themselves, which my research aims to contribute to by considering the significance of the materiality of Gagnon's photographs through an analysis of his choice of cameras and printing techniques.

There are two other texts, which examine Gagnon's photographs in detail. The first, by curator and photography historian Olivier Asselin, is a detailed analysis of twenty four photographs, through which Asselin speaks to the poetic and symbolic aesthetics of the artist's work. In Le Flâneur et l'Allégorie: Essai sur la Photographie de Charles Gagnon, he proposes that "most photographs by Charles Gagnon perhaps are enigmas." 10 Their allegorical meaning, he points out, differentiates them from other works within the documentary tradition, which also influenced Gagnon's photographic work. Asselin's text mainly discusses the aesthetic characteristics of the photographs and the meaning that can be derived from them. Each photograph in the book is accompanied by a visual analysis, which are applied as support material for Asselin's eight chapters. In each he addresses an aspect, a theme or a motif of Gagnon's photography under the headings: 'Histories', 'Landscapes', 'Allegories', 'Theologies', 'Cities', 'Deserts', 'Figures and Narratives' and 'Displacements'. This visual analysis is useful in framing the reading of Gagnon's photography. While it is evident that the photographs in the AGO's collection do not function as simple documents, Asselin thoroughly teases out the aesthetic dynamics Gagnon was working with, an important starting point in using them as objects of research.

\footnotetext{
${ }^{10}$ Olivier Asselin, Le Flâneur et l'Allégorie. 9
} 
Canadian photography theorist and historian Penny Cousineau-Levine expands upon Gagnon's photographic metaphors referred to by Asselin, in her book Faking Death : Canadian Art Photography and the Canadian Imagination. The text is an attempt to demonstrate an underlying thematic Canadian tradition in photography. This notion is useful in my thinking through Gagnon's photographs as Canadian work. The ideas are divided thematically into cultural notions that Cousineau-Levine believes represent a Canadian mentality. Gagnon is heavily present in all of the book's chapters, demonstrating her belief that his work is crucial to understanding the history of art photography in Canada. Some of the conclusions drawn by Cousineau-Levine between the work and what it means to be Canadian are strangely morbid and seem to me far fetched and are not necessarily relevant to my use of this text. While she uses notions of death as pathology to advance an argument I do not necessarily agree with, Cousineau-Levine's visual analysis of Gagnon's photographs is nevertheless detailed. She examines some of the common visual themes represented in them, such as the window as an important aesthetic thread connecting his work, particularly evident in the SX-70 series. ${ }^{11}$ This book includes the largest analysis of his photographs in a text not associated with an exhibition. It is important to note, however, that the Minox and SX-70 photographs are again under represented. Gagnon's work appears in context next to other Canadian practitioners of the 1970's, which also provides a view point of the artistic climate within which he was working.

Charles Gagnon: Observations, the catalogue for the 1999 exhibition of the same name presented at the Musée du Québec, brings two writers together in one volume. Penny-

\footnotetext{
11 Penny Cousineau-Levine. Faking Death. 89
} 
Cousineau's catalogue essay is, in a way, a precursor to her argument in Faking Death. She begins with a strong statement that the photographs exhibited not only provide personal insight on the artist but represent a larger "collective Canadian imagination." 12 She provides a compelling argument for differencing Gagnon's work from the American tradition of the 'social landscape', and, perhaps forcefully, attributes it to a Canadian tradition. Gagnon's sensibilities as an artist come through much more clearly in the second part of this catalogue, which consists of a transcribed interview between Oliver Asselin and the artist. Gagnon's approach to photography is addressed throughout the interview, how and why he photographs. Rather than concentrating on any sort of chronology, this transcribed interview provides much more pertinent information regarding Gagnon's philosophical inspirations as an artist and the place that photography takes within his way of looking at the world.

The Minox and SX-70 works are what makes the AGO's collection of Gagnon photographs unique. Overall, these works have not been considered in the scholarship of the artist's work, which has concentrated on the aesthetics of the $35 \mathrm{~mm}$ camera images. What stands out in these two types of photographs, however, are the methods by which the Minox and SX-70 images were made. In order to examine the works more closely, it is important to understand the technology that made them possible. In her essay "Instant Photography: The Allure and the Legacy," from The Polaroid Years : Instant Photography and Experimentation, curator of photography at the Vassar College Art Centre, Mary-Kay Lombino, explores the many creative ways in which artists have used Polaroid photography as a means of expression between 1972 and 2011. With a brief history of the process, she specifically outlines the impact of the SX-70

\footnotetext{
12 Cousineau-Levine. 11
} 
format, which was brought to market in 1972. This history is illustrated in greater detail in Christopher Bonanos' 2012 book Instant: The Story of Polaroid. It is important to understand how the SX-70 camera functions in order to analyze the images it produced. Lombino and Bonanos both discuss the work of artists working with Polaroid in different ways, such as physical manipulation of the print, montage, conceptual projects and abstraction. The latter is particularly useful in thinking through Gagnon's work. Lombino looks at the work of Victor Raphael, Lucas Samaras, and Grant Worth, among others. ${ }^{13}$ While all are American artists, the analysis is a good resource in understanding how Gagnon's Polaroid photographs were made at a time when many other North American artists were experimenting with the medium. While there is not a lot of literature concerning the artistic use of the Minox camera, the Minox C Owner's Manual (1969) can be used to understand how the small-format camera was used by Gagnon. Additionally, Rolf Kasemeier's Small Minox - Big Pictures is the quintessential guidebook to using the Minox camera. In this book he gives a brief history of its invention in 1938, details on its components, how to operate it, and guides regarding printing and enlargements.

There is limited scholarship available about Charles Gagnon's small-format photographic work. However, there is sufficient information available to frame this research and help me analyze these two groups of work within the larger context of the artist's practice. By researching the history of art photography is Canada, Gagnon's exhibition history and the scholarship around it, as well as the history of the technology involved in the making of his two types of images, I will be able to discuss how these groups of work can be useful in contributing to the scholarship around Gagnon's practice. This discussion will be formed by considering Gagnon's multi-

\footnotetext{
${ }^{13}$ Mary-Kay Lombino "Instant Photography” 10-15
} 
disciplinary practice, his engagement with the concepts of 'input' and 'output', the genre of landscape, and the motif of the window. 


\section{Chapter I : The Philosophy of a Multi-Disciplinary Practice}

In order to address the role of the Minox and SX-70 photographs, it is important to have a general understanding of Charles Gagnon's approach to art making. The multi-disciplinary aspect of his practice is significant to his way of navigating the world as an artist. His interests ranged from painting and photography to film, design, music, ancient cultures and philosophy. These distinct ways of thinking give his work plurality, wherein components come together to form a whole. The harmony of this whole is not easy to decipher but it is undeniably felt throughout the work and is aligned with Gagnon's philosophical approach to the world, which is deeply rooted in the transcendental and the metaphysical. In turn, his philosophical concerns give the work a certain sensibility that borders on the spiritual. He has states that art is more like communion than communication. ${ }^{14}$ Gagnon's attraction to the apparatuses of the Minox and SX-70 cameras can be linked to these concerns.

It is useful to consider Gagnon's time in New York City, where he lived and worked from 1955 to 1960 , his formative years ${ }^{15}$ - formative not only stylistically but also in shaping a multidisciplinary approach to conceiving work. After reading an article in Time magazine about the contemporary New York school of art, illustrated with the work of Robert Motherwell, Jackson Pollock and Mark Rothko, Gagnon was inspired to move to New York City ${ }^{16}$. While pursuing

\footnotetext{
14 Normand Thériault Introduction to Charles Gagnon: Une Exposition Organisée par le Musée des Beaux-Arts de Montréal. 5

15 Fry. 44-62

16 Laurent Lamy and Charles Gagnon, L'Art Aujourd'hui. 8:10-8:36
} 
his studies at Parsons School of Design, he began producing a lot of painting and photography ${ }^{17}$ He became fascinated by graffiti on the city's walls, which he photographed extensively (Fig. 3). These walls would become the inspiration for some of his Calligraphic paintings such as Vol Nocturne \#1 (Fig,. 4). Very early in his career, his photographic observations of the urban environment were informing his painting practice..$^{18}$

Gagnon also sought inspiration from an environment quite different from New York City alleyways, the Metropolitan Museum of Art. He would become fascinated by some of their ancient art collections, specifically the Egyptian hieroglyphs, which are in many ways, similar to the painted marks Gagnon found so interesting. ${ }^{19} \mathrm{He}$ was intrigued by codes he could not decipher. Years later, in the 1980's, viewers would be tasked with deciphering Gagnon's own linguistic codes as he used language on his canvases.

These sources were not the only influences on Gagnon while in New York. He also embraced Eastern philosophy, particularly Zen Buddhism, which he encountered through the books of Daisetsu Teitaro Suzuki. ${ }^{20}$ These concepts would influence much of his creative production but because Gagnon did reference much of his philosophical sources, it is difficult to trace their exact influence. The point is that this was a time where Gagnon was exposed to a multitple ideas and practices, from hieroglyphs to the music of John Cage. ${ }^{21}$

\footnotetext{
${ }^{17}$ Fry. 44

18 Fry. 47

19 Ibid. 45

${ }^{20}$ Ibid.

${ }^{21}$ Geoffrey James “On the Work of Charles Gagnon.” 13:45-13:50
} 


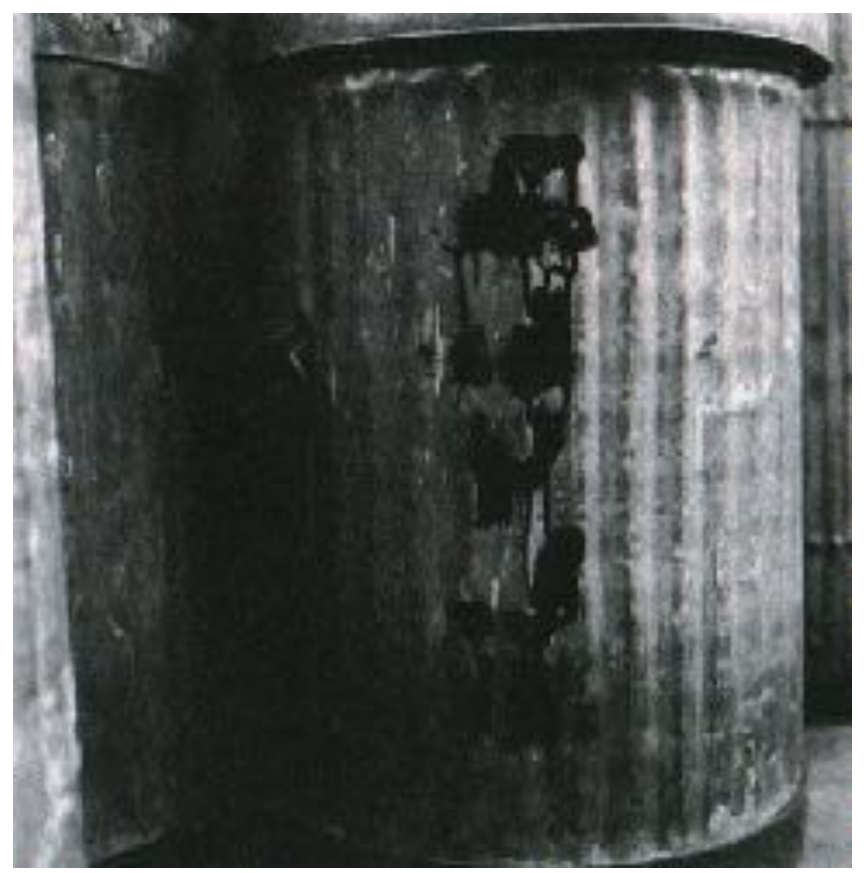

Fig. 3

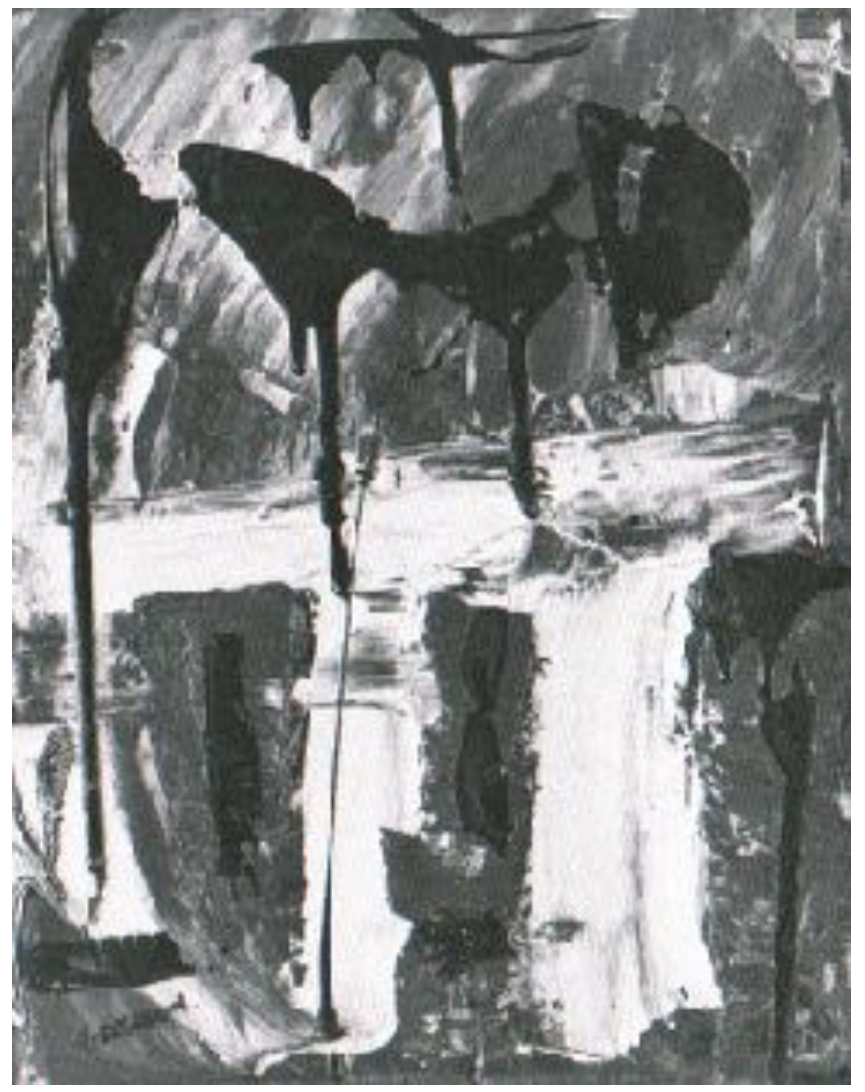

Fig. 4 
Multi-disciplinary tendencies became more common throughout the 1960's and 1970's. A shift from the modernist to the post-modernist mentality affected the work of artists as well as the ways in which it was exhibited. Paintings by the abstract expressionists that Gagnon encountered during his years in New York were championed by art critic Clement Greenberg. He provides a definition of modernism in his 1961 essay titled 'Modernist Painting,' in which he defines modernism as "the use of characteristic methods of a discipline to criticize the discipline itself, not in order to subvert it but in order to entrench it more firmly in its area of competence." 22 This statement assumes the complete and distinct categorization of the separate mediums of art-making. However, during the decade following Greenberg's publication, artists began to blur these lines between different mediums. In Canada, Michael Snow and Joyce Wieland were at the forefront of this movement in their simultaneous use of painting, photography, sculpture and experimental film. By the 1970's such practices were no longer on the fringe of the art world but very much at its centre as seen in the Museum of Modern Art's 1978 exhibition Photography Into Sculpture. ${ }^{23}$ While Gagnon's painting and photography did not come together into singular works until the 1990's with the series Histories Naturelles and Ex Situ, his multi-disciplinary approach from the 1960's and 1970's can be linked to this change in mentality. It transformed his artistic milieu at a time where photography was only beginning to be recognized as a proper art form by major institutions.

\footnotetext{
22 Clement Greenberg, "Modernist Painting."

23 Statzer.
} 
Gagnon has stated that these years were "important in the development of all art forms, including music, dance, literature, etc." ${ }^{24}$ This range of interest is quite telling of his approach to art-making throughout the oeuvre. Referring to a type of classical musical composition, Gagnon titles a painting Cassation in 1976. This concept of plurality is in line with Gagnon's personal philosophy, which in turn stimulated his photography.

In order to better understand Gagnon's philosophy, we should take into account a 1998 interview between the artist and art historian Olivier Asselin, published in the catalogue for the retrospective of Gagnon's photographic work, Observations. Asselin's approach to this interview reveals the philosophical relationships within Gagnon's oeuvre. He explains in the introductory text that rather than being concerned with biographical matters or even the connection between Gagnon's photography and painting, “it seemed to [them] more useful to concentrate on [Gagnon's] conception of photography and on all the reflexion created by this way of looking, which only photography makes possible." ${ }^{25}$ The way Gagnon expresses his thoughts about the medium is at the centre of their conversation and provides insight into his way of navigating the world as an artist.

In discussing when he photographs, Gagnon explains that earlier in his life he used to have his camera on him most of the time. The photographs, however, as Asselin points out, are often taken outside of Quebec. This observation prompts Gagnon to explain why this might be:

\footnotetext{
24 Lamy and Gagnon. 9:35-9:44

25 Olivier Asselin, and Charles Gagnon, "Coïncidences. Conversation Avec Charles Gagnon."117
} 
"When you travel, you are freed of every-day things. In your relationship to things, you live a sort of cultural shock. You notice some things that you have never seen. I think that the spirit becomes much more sensitive. It is perhaps in part to protect yourself, because you could very well find yourself in a hostile situation. But I think the availability is important."26

This idea of displacement is in fact the subject of one of Asselin's chapters regarding the artist's work in his book Le Flâneur et l'Allégorie. ${ }^{27}$ Gagnon took many photographs while travelling because the change in environment allowed him to become aware of his surroundings in a new way. A seemingly mundane object might suddenly become visually intriguing when its surroundings are unfamiliar. The Minox and SX-70 photographs, however, break this pattern of Gagnon only practicing photography when he did not have access to his studio. Most of the former were shot in the streets of Montreal, while the latter were entirely taken from a single location, Gagnon's house. While the change in environment is crucial to the $35 \mathrm{~mm}$ photographs, the camera apparatus used in the production of the two other groups of photographs is what provided Gagnon with a different way of seeing his surroundings.

Some of the ideas he expresses when talking about photography while traveling is also telling of the metaphysical nature of Gagnon's philosophy as an artist. The sensitivity of his spirit, while photographing, is one facet that he touches on a few times over the course of this interview. He explains that he has never sought out photographs, rather the "situation imposes

\footnotetext{
26 Asselin and Gagnon. 117

27 Ibid.
} 
itself on him," a kind of "revelation" as he calls it, before comparing himself to an archeologist. ${ }^{28}$ Through his photographs, Gagnon discovers the world, much like archeologists discovered the ancient Egyptian hieroglyphs-marked walls that now reside in the Metropolitan Museum of Art. These moments that Gagnon notices with his camera, create discursive spaces, where the objects seem to speak to each other in connecting ways. He does not believe in the "myth of inanimate objects," as he calls it..$^{29}$ To him, everything is alive through energy and movement.

Asselin proposes that Gagnon's 35mm photographs become "conversation pieces," $30 \mathrm{a}$ phrase he does not care to translate into French. This, of course, is a play on words, as the images not only prompt conversation, but in fact, conversations seem to be occurring within them. The objects in conversation are often highlighted in the title of the photograph. Theatre Marquee with Garbage Bags (Fig. 5) depicts a group of bulbs lighting a group of bags, which through their opacity refuse to be exposed, they contain trash after all. Yet, they are neatly piled up to create a wonderful form that lines up to the adjacent staircase, which supports the structural integrity of the pile. The objects in this image are not only conversing through form, but also through action. This is a stationary image, yet it seems active - or alive as Gagnon would see it - because of these relationships. The conversational aspect of photographs like this one speaks to the multidisciplinary nature of Gagnon's work, where the many practices converse. Much of the work seems to come from the motivation of seeing something, which might already exist, in a new

\footnotetext{
${ }^{28}$ Asselin and Gagnon. 117-118

29 Ibid. 119

${ }^{30}$ Ibid. 120
} 


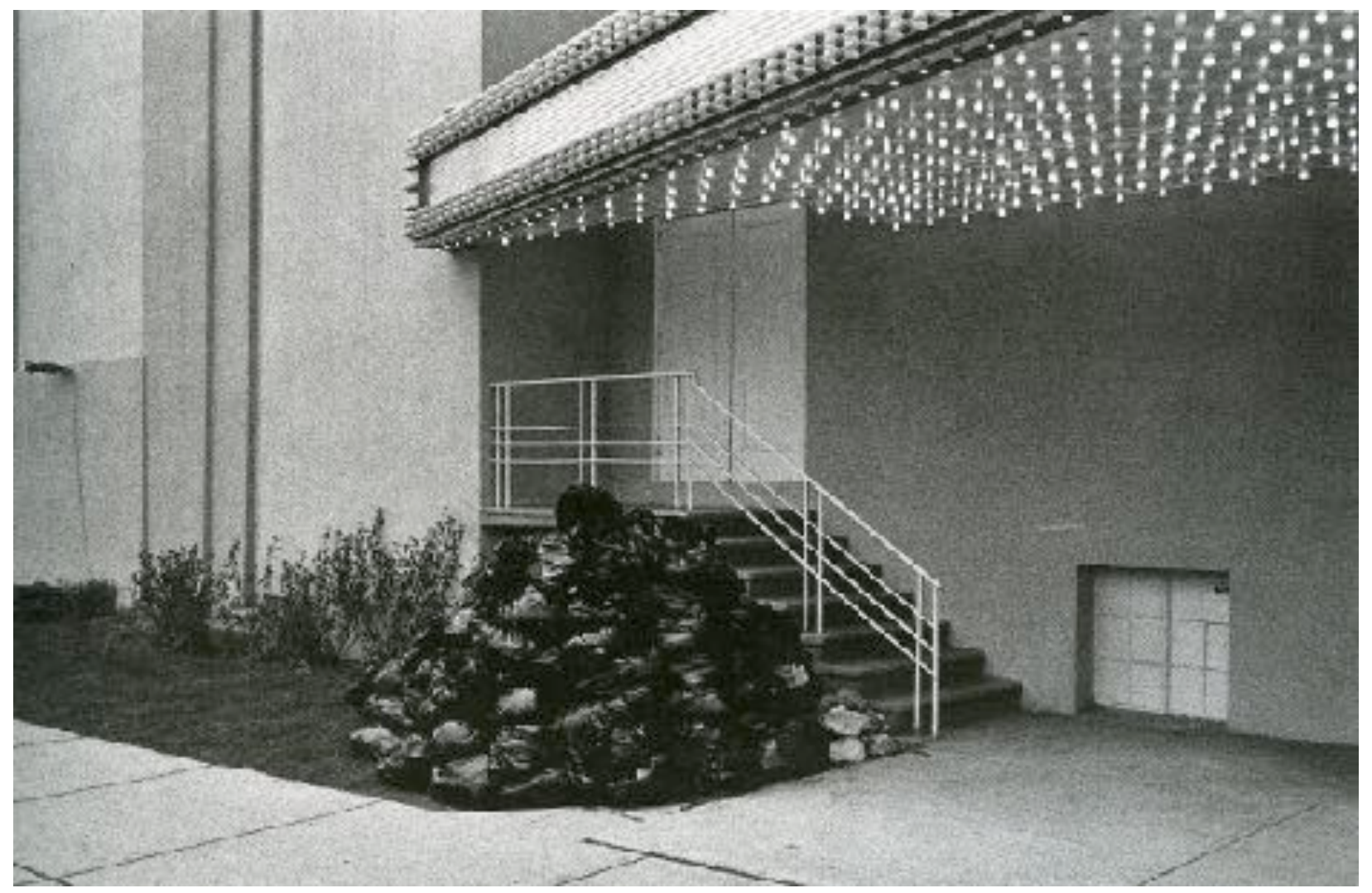

Fig. 5

way. Conversely, when it comes to the Minox and SX-70 cameras, this new way of seeing is much more literal, one sees the world differently through the viewfinders of these two cameras, as will be discussed in the following chapter.

The language of these photographic conversations, however, remains ambiguous. The objects in Theatre Marquee with Garbage Bags create a dialogue with no clear meanings but that might be described as codes, which require deciphering, something each viewer will approach differently. This ambiguity is, in fact, central to the artist's oeuvre. Gilles Toupin's review of Gagnon's exhibition at the Musée des Beaux Arts de Montréal in 1978 was titled 'Des Fenêtres 
sur l'Ambigu' (Windows onto the ambiguous). ${ }^{31}$ Gagnon himself would confirm this the same year when he says that his work is "completely based on ambiguity, and has always been." 32 This ambiguity is significant to the multi-disciplinary quality of Gagnon's work.

Philosophically, Gagnon's embracement of ambiguity points to a certain fluidity in his way of connecting his many different artistic practices.

31 Gilles Toupin, "Charles Gagnon : Des Fenêtres Sur L'Ambigu."

32 Lamy and Gagnon. 15:24-15:31 


\section{Chapter II : Input / Output}

Gagnon's Minox and SX-70 photographs are produced very differently than his $35 \mathrm{~mm}$ work. The process of image-making changes when the apparatus used functions with distinct characteristics. This is very much the case for these two cameras. Before addressing the specific ways in which they operate, it is important to consider the differences in Gagnon's painting and photographic art-making processes. The two groups of photographs at hand make us re-assess the characteristics of his artistic productions: the portable Minox camera emphasizes Gagnon's observational approach to the photographic medium, while the instantaneous Polaroid SX-70 mediates the complex relationship between the taking and the making of a photograph.

In 1979, Gagnon told art critic Laurent Lamy in an interview on Radio-Canada's radio program 'l'Art Aujourd'hui', that when he photographs, he enters a "period of input," where he can observe from behind the photographic apparatus without physical engagement and manipulation of the world in front of him. On the other hand, he uses the term "output" to describe the periods where he is painting in his studio. He does not like the verb creating but prefers to think of his painting work as manipulations of materials that already exist. ${ }^{33}$

The concept of 'input' and 'output' is most commonly associated with computing, where interactions function through acts of human 'input' being translated by a machine, which produces an understandable 'output' message. ${ }^{34}$ The modern camera functions similarly. The

\footnotetext{
33 Lamy and Gagnon. 17:36-18:56

34 Linda Null and Julia Lobur. The Essentials of Computer Organization and Architecture. 185
} 
push of the shutter is the 'input', which through a series of mechanisms inside the apparatus produces the 'output', the image on a piece of film.

Gagnon, on the other hand, looks at input and output as separate processes. Although, considering the influence his photography has had on his painting, which he has claimed is more significant than the opposite, perhaps a causal relationship does exist between the two. ${ }^{35} \mathrm{He}$ believes that photography is an act of input because of the lack of physical engagement involved. ${ }^{36}$ This opposes modernist convictions that value the qualities of the photographic print, which can be manipulated in the dark room. Gagnon, though he developed the film and made the prints himself, never cropped or altered his photographs. This becomes clear upon examining the Minox negatives beside their corresponding print. The SX-70 photographs are also un-altered because of the nature of Polaroid technology. While the emulsion can be manipulated shortly after exposure, to feature a painterly quality, one cannot seamlessly crop or edit the image. Gagnon claims to be an observer, not a maker, when he photographs, performing 'input' rather than 'output' like in his paintings.

These two cameras produce images with very different characteristics. In order to clarify how these photographic works relate to Gagnon's idea of photography as an act of input, we must further examine the technology used in their production. Both of these apparatuses function differently from traditional camera operation and therefore produce distinct images from a $35 \mathrm{~mm}$

\footnotetext{
35 Fry. 25

${ }^{36}$ Lamy and Gagnon,. 18:18-18:27
} 
single lens reflex (SLR), which Gagnon used to make most of his other photographic work. While looking through the lens of these two cameras, different worlds can be discovered.

The Minox advanced the innovation of the portable camera tradition. Despite its reputation as a spy camera, it was not meant to be a 'secret' or 'hidden' camera. The Minox was designed for amateurs who desired to carry a camera everywhere they went without the cumbersome setbacks. The first model was released in Germany in 1938 under the name 'Riga Minox'. It was the first sub-miniature camera, using a negative only 9x $11 \mathrm{~mm}$ in size. Even with such a small frame size, the camera was designed to produce detailed images with the use of a high quality lens and an ingenious shutter system that allowed for the camera body to be so small. ${ }^{37}$ After the Second World War, the Minox GmbH company improved upon the original design. In 1948, a new factory was built to manufacture every part of the new Minox camera. The design of the apparatus remained very close to the original, with improvements made along the way. Most notably, the camera was synchronized to be used with flash in 1954. The Minox B (Fig. 6), was released in 1958 and was equipped with a light meter, making it easier to control exposure levels. From then on the Minox sub-miniature cameras remained extremely similar, only adding electronic light meter and shutter technologies but refraining from changing the design or principle settings of the camera. ${ }^{38}$

\footnotetext{
37 Rolf Kasemeier, Small Minox, Big Pictures. 25

38 Kasemeier. 26
} 


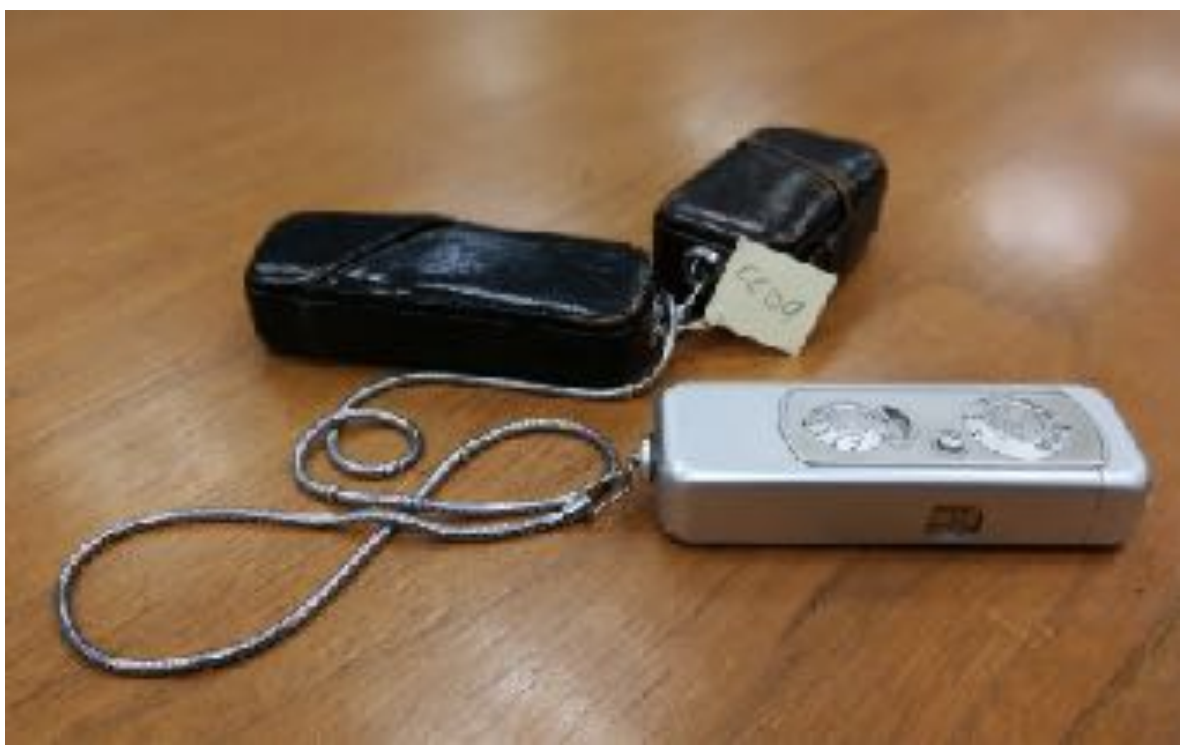

Fig. 6

The Minox camera is extremely small $(8.2 \times 2.9 \mathrm{~cm})$ and its size is partly what attracted Gagnon to this photographic apparatus. In a 1979 interview with photography scholar Katherine Tweedie, he notes that "with a camera slung over your shoulder and photographer branded on your forehead, there is a certain pressure to go out and make pictures, which shouldn't be the point of carrying a camera; the camera should be there, in case you see something. The Minox is small, it's unpretentious, you can be amused." 39 The Minox camera's portability and discreetness allowed Gagnon to photographically observe the world more freely. The apparatus relieved him of the modernist pressures of the $35 \mathrm{~mm}$ format and let him fully engage in his process of input. However, the Minox is a very particular camera to operate. The viewfinder is so small that it is quite difficult to look through it, and often the results are variances of the image the photographer envisioned. This often creates a tilt in the image, which can be seen in photographs like $M N$ : XXIII-30-77 (Fig. 7). This aesthetic augments the spontaneous quality of these photographs. The Minox also has some particularities that make it interesting as an optical

\footnotetext{
39 Katherine Tweedie, "Photography in Québec” 126
} 
object. The shutter is cocked and the film is advanced by sliding the camera in and out again, open and shut, a process very similar to the blink of an eye. This feature as well as its size make this apparatus a very close extension to the photographer's eye. It provides Gagnon with a novel way of seeing the world photographically. This more experimental approach, with all its quirks and visual concerns, increases Gagnon's possibilities to discerning urban environments in inventive ways, more so than the $35 \mathrm{~mm}$ camera format. The characteristics of the world as seen through the Minox allows for what Gagnon has explained as "a sort of fusion," where "multiple levels of reality coexist, which can be, in many cases, contradictory." 40

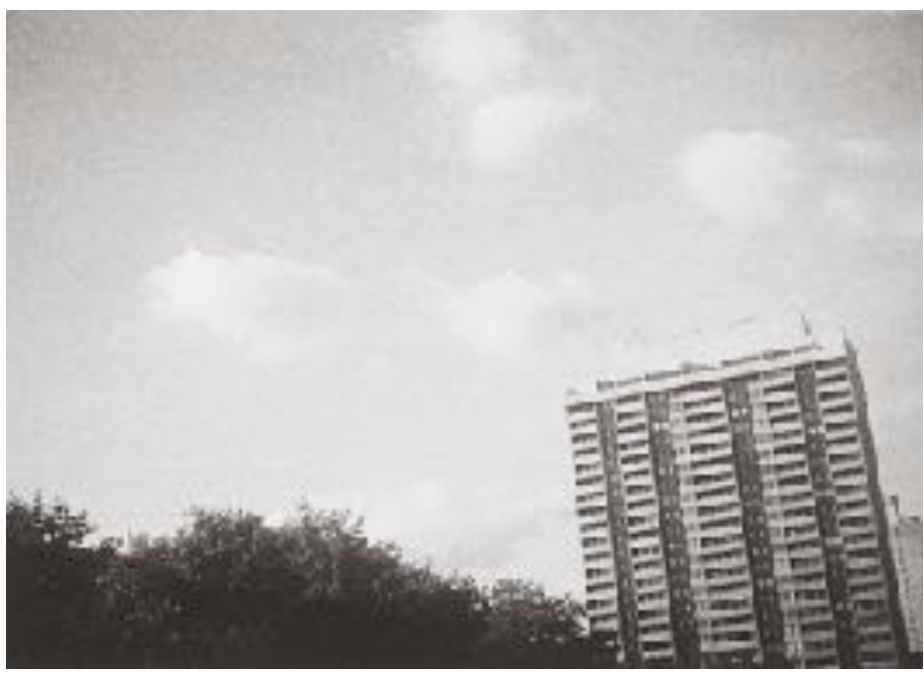

Fig. 7

40 Assselin and Gagnon. 118 
In 1943, Edwin Land began his quest to create an instant photographic process that would no longer require the use of a darkroom. He was the founder and president of the Polaroid corporation, which began as a manufacturer of polarizer technology. ${ }^{41}$ Four years later, in 1947, Land demonstrated the instant photography process to the world for the first time, using a modified view camera. ${ }^{42}$ By 1948, the first Polaroid camera, model 95, was on the market. It could produce a positive photograph from a peel-apart negative backing in only sixty seconds. It would take the company another twenty four years to eliminate the need to peel off the negative. ${ }^{43}$

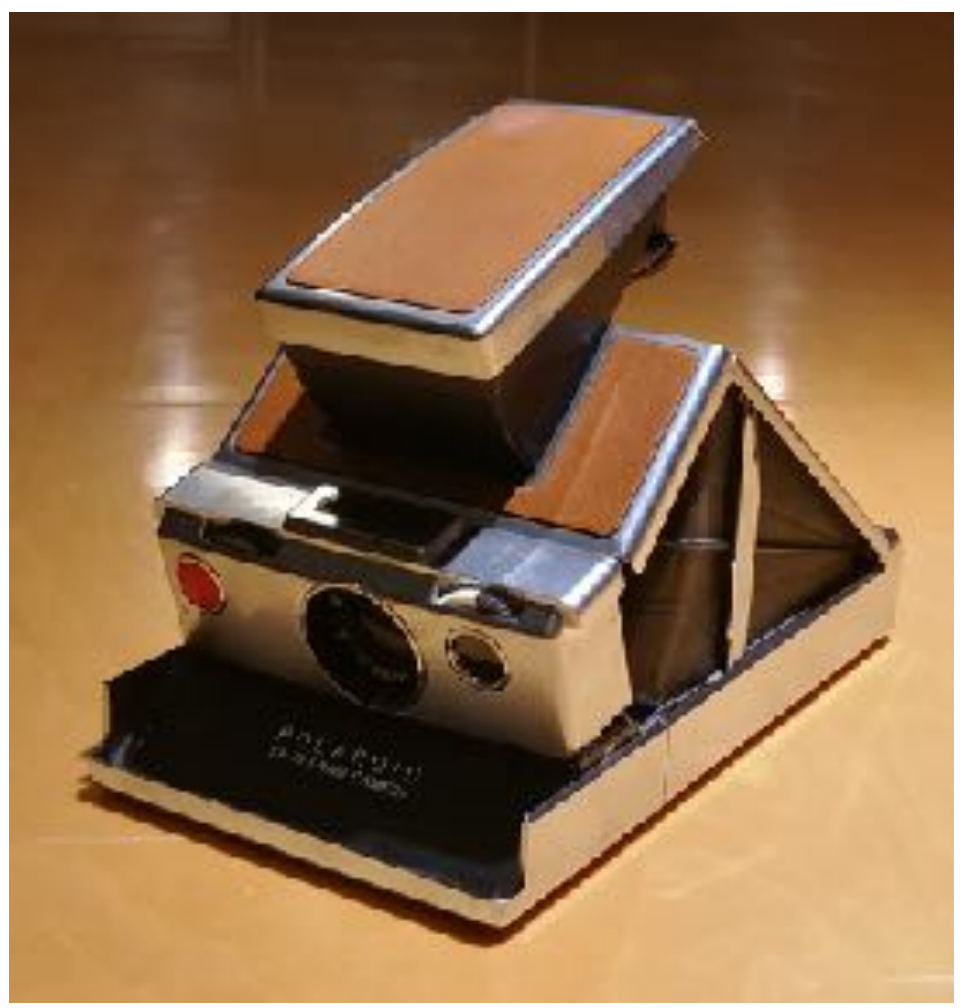

Fig. 8

\footnotetext{
${ }^{41}$ Christopher Bonanos, Instant: The Story of Polaroid. 25

42 Ibid. 39

43 Ibid. 42
} 
The Polaroid SX-70 model (Fig. 8) was released in 1972 and quickly became a very popular camera on the market. It produced the first fully integral instant photographic print. The entire developing and printing process occurs within the film's structure without the need for intervention from the user. Both the negative film and positive print are imbedded between two layers of protective plastic, clear on the front and black on the back, keeping all of the materials contained within a singular object. All the photographer was required to do was press the shutter release button. It was also the first camera to produce the white-bordered print that would become the most recognizable characteristic of a Polaroid photograph. The SX-70 quickly became an important part of photographic culture. It was featured on the cover of LIFE magazine soon after its release in one of the most iconic photographs of Edwin Land (Fig. 9). ${ }^{44}$

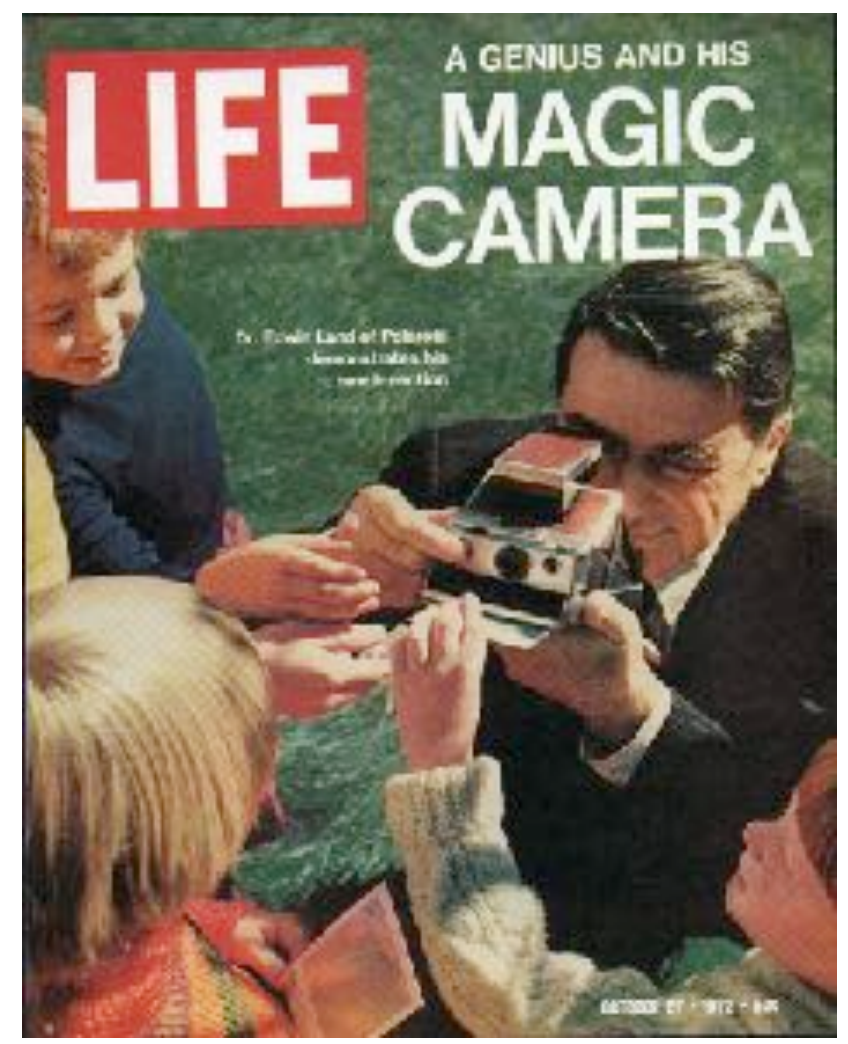

Fig. 9

44 Bonanos, 88-95 
The SX-70 is a simple Polaroid camera in terms of operation, but it also provided some professional appeal. The focus for the camera's very sharp lens was manually set with the use of a knob. While previous Polaroid cameras' focus was also set manually, the SX-70 provided a much smoother focusing process and a larger range, from infinity down to ten inches. The focus, as in other SLRs, is easily adjustable as the viewfinder displays the exact image seen by the camera lens. This particular attribute might be a reason why so many artists were attracted to this camera. Looking at Glass Blue Birds (Fig. 10) by André Kertész, who was an avid enthusiast of the camera, it is evident that the camera could be used to create high quality photographic prints with plentiful depth of field. ${ }^{45}$ Similarly, the manual focus of the SX-70 allowed Gagnon to produce a sharp background, while the foreground of the photographs remain soft.

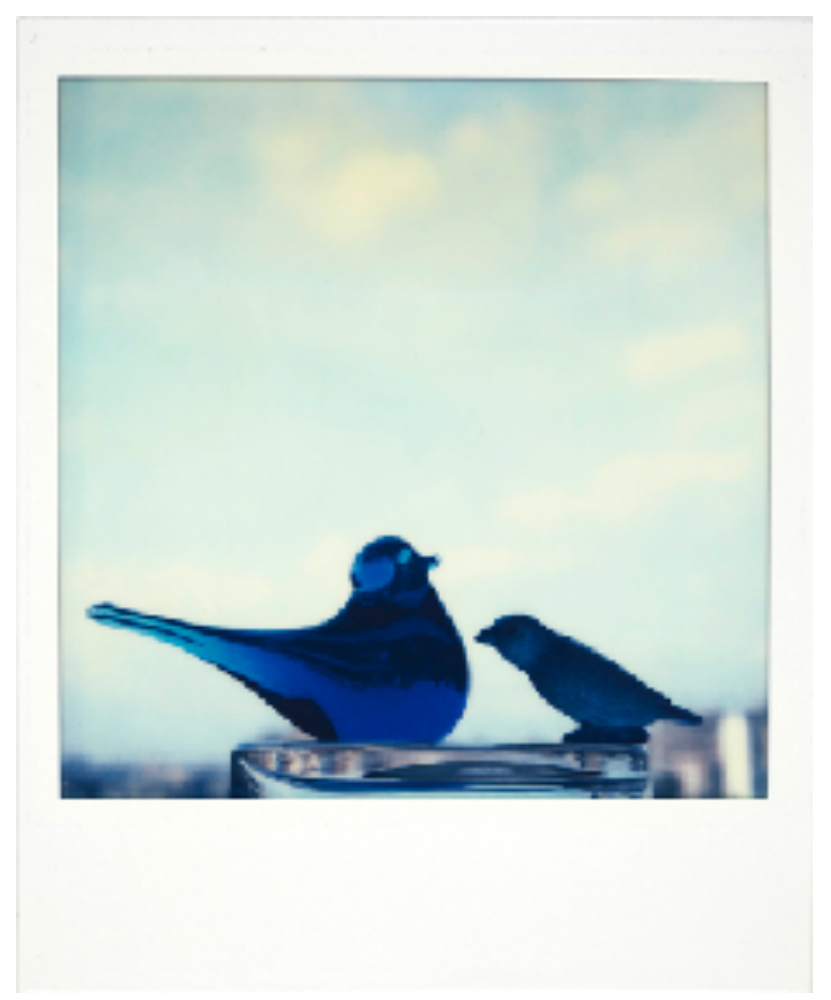

Fig. 10

45 Bonanos. 101 
Land wanted to create an SLR camera that was also portable, which resulted in the foldable SX-70 camera. A complex set of mirrors inside of the apparatus make this possible as is illustrated in a still from Ray and Charles Eames' 1972 promotional film for the camera (Fig. 11). ${ }^{46}$ It is an incredibly ingenious system. The way that the camera is constructed, however, gives its viewfinder some particularities. Users must look through the viewfinder straight on in order to have a proper view of what they are photographing. Both of the Minox and SX-70's viewfinders are somewhat difficult to look through, creating a challenge for the photographer. Perhaps it is also these anomalies in viewing features that attracted Gagnon to these particular apparatuses in a different way than the $35 \mathrm{~mm}$ camera.

Most importantly, however, the instantaneous quality of the SX-70 was unprecedented. It allowed artists to take a photograph, quickly evaluate the result before taking another. The input of light and output of the image, which make up the basic dynamics of photography, are brought together, in an almost simultaneous moment, with the SX-70 Polaroid camera. This made its prints well suited to create studies, or photographic sketches. It is very clear, however, that Gagnon's SX-70 photographs were not mere studies, but final works of art. Each 10.8 x $8.8 \mathrm{~cm}$ print is numbered, stamped and signed on the verso (Fig. 12) and matted to show only the image. There is a clear intention to create images that capture the subject of the photographs in ways made possible by the characteristics of these two cameras. Gagnon' choice of subject matter in the Polaroids, as will be discussed further, is deeply related to the photograph's materiality: the protective plastic layer and white border.

46 Bonanos. 102-103 


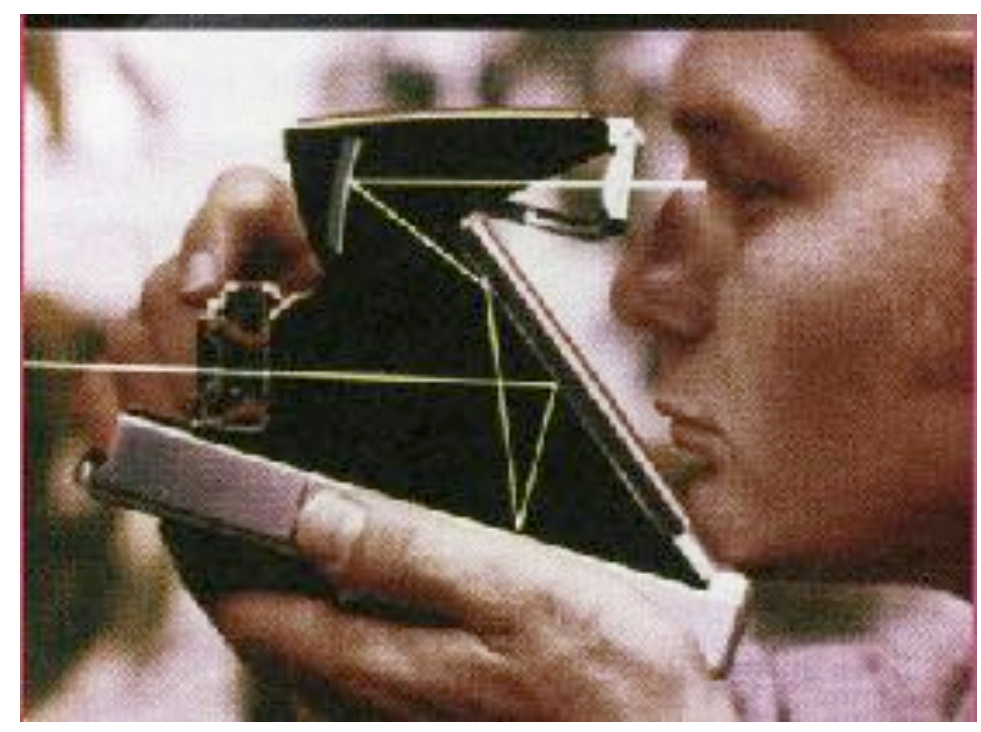

Fig. 11

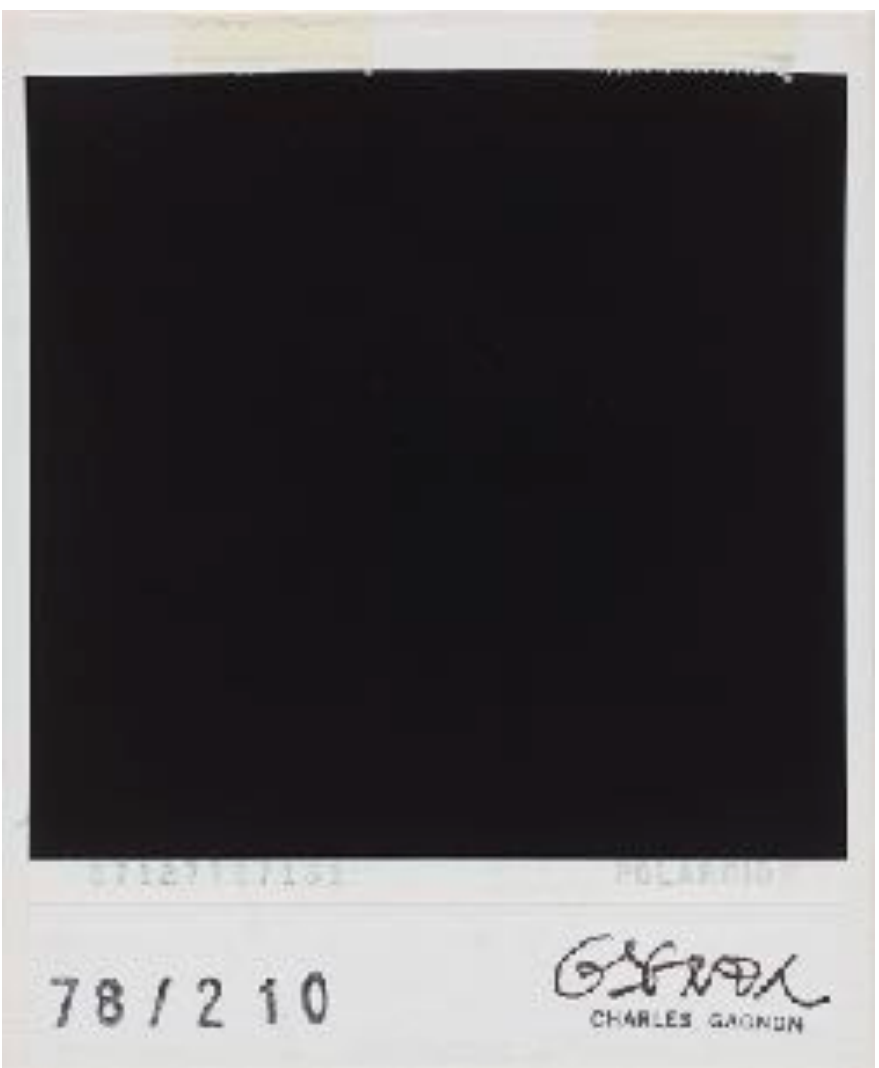

Fig. 12 


\section{Chapter III : Landscape, Re-Imagined}

It may seem strange to use the term 'landscape' to talk about an artist who was mostly engaged with abstraction. The idea of landscape, however, is an important aspect of Gagnon's oeuvre. While his painting practice remains non-figurative throughout his career, the works have been discussed as deeply connected to notions of landscape. The way in which he applies paint to the canvas, as well as his colour schemes, are reminiscent of certain traditions of landscape painting. His photographs, on the other hand, address landscape in a more representational way through their subject matter. The 1970's saw photographic practices challenging pre-existing notions of landscape in order to think about humans' relationship to their urban environment. The Minox and SX-70 cameras allow him to engage in a similar exercise but he used them to focus on the relationship between natural and human-made environments. These relationships, which often become more complex as more time is spent with the images, bringing out the plurality in concepts that is so central to Gagnon's work.

In 1966, Nathan Lyons, photographer and curator of the George Eastman House in Rochester, New York, curated the ground-breaking exhibition Towards a Social Landscape. The exhibition featured the work of Bruce Davidson, Lee Friedlander, Garry Winogrand, Danny Lyon and Duane Michals, five photographers working within what would have been defined as the 'documentary' genre. The photographs mostly represented people integrated in their environment. With this exhibition, Lyons advocated for a re-evaluation of the idea of landscape as being centred around the natural. In the catalogue, he quotes Gyorgy Kepes's book The New 
Landscape in Art and Science, when he writes that our notions of landscape should instead include a "nexus between man and man, and man and nature." 47

Gagnon's 1971 visit to attend Robert Frank's Apeiron Workshop led to him meeting some of the 'social documentary' photographers. ${ }^{48}$ Even prior to this visit, however, the influence that this kind of photography had on his work is evident when comparing it to some of the photographs from Toward a Social Landscape. Both Friedlander and Gagnon repeatedly photographed storefront windows. Their similar exploration of transparency and reflection can be seen in Staten Island, 1963 (Fig. 13) and Miroiterie - N.Y., 1969 (Fig. 14). These photographs remind us of French photographer Eugène Atget's work from 1925 and 1926, in which he photographed the reflective storefronts of clothing shops on the streets of Paris. This shows that such photographic impulses were not novel to this period of production, but by the late 1960's and 1970's, such imagery began to be recognized as part of our idea of landscape.

The automobile plays a major role in Gagnon's photographic work, whether the photographs depict it or are taken from within a car. Autoroute New York, près d'Albany, 1966 (Fig. 15) is reminiscent of Winogrand's iconic photograph Los Angeles, 1964 (Fig. 16). Both photographs are taken from a moving car and depict the adjacent moving car. The automobile often is a centre piece of post-war North American life, and the common way of navigating both the urban and natural landscapes that make up the enormity of the continent. The influence of

\footnotetext{
47 Nathan Lyons, Towards a Social Landscape. 6

48 Geoffrey James. 19:16-19:30
} 


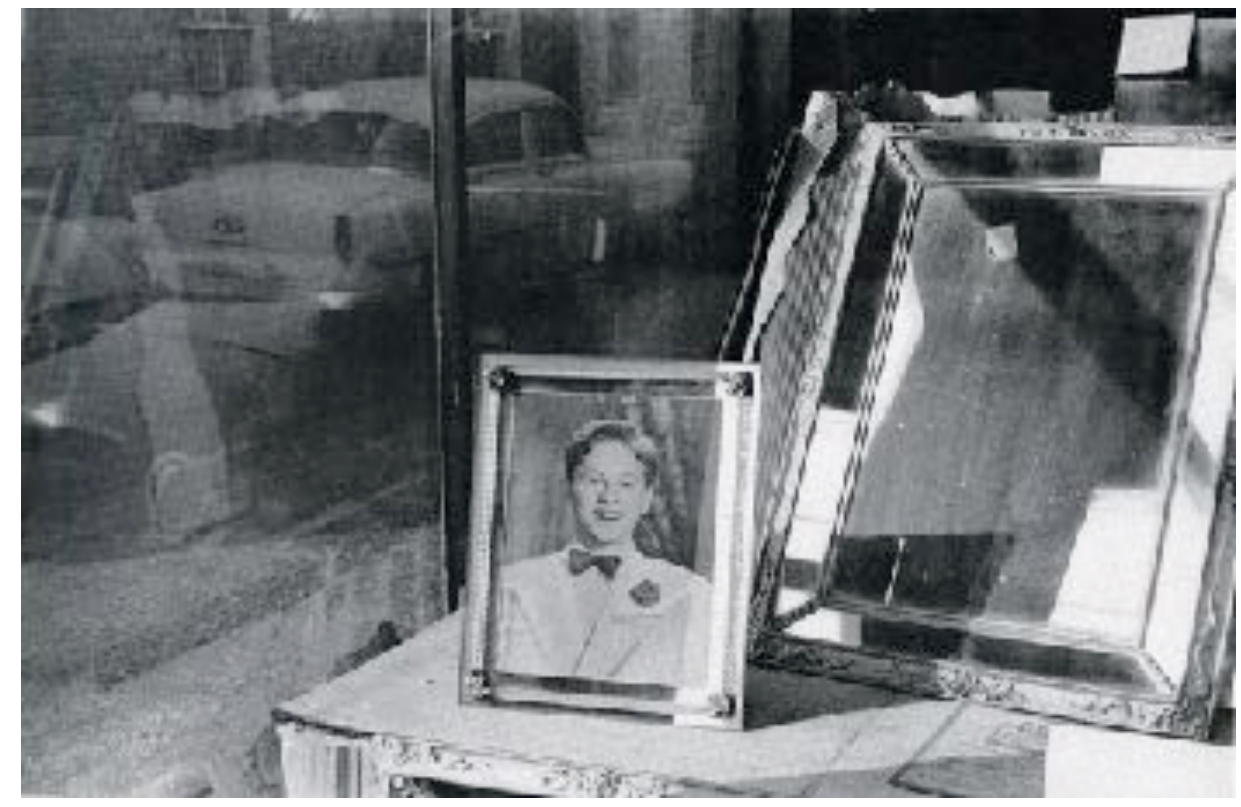

Fig. 13

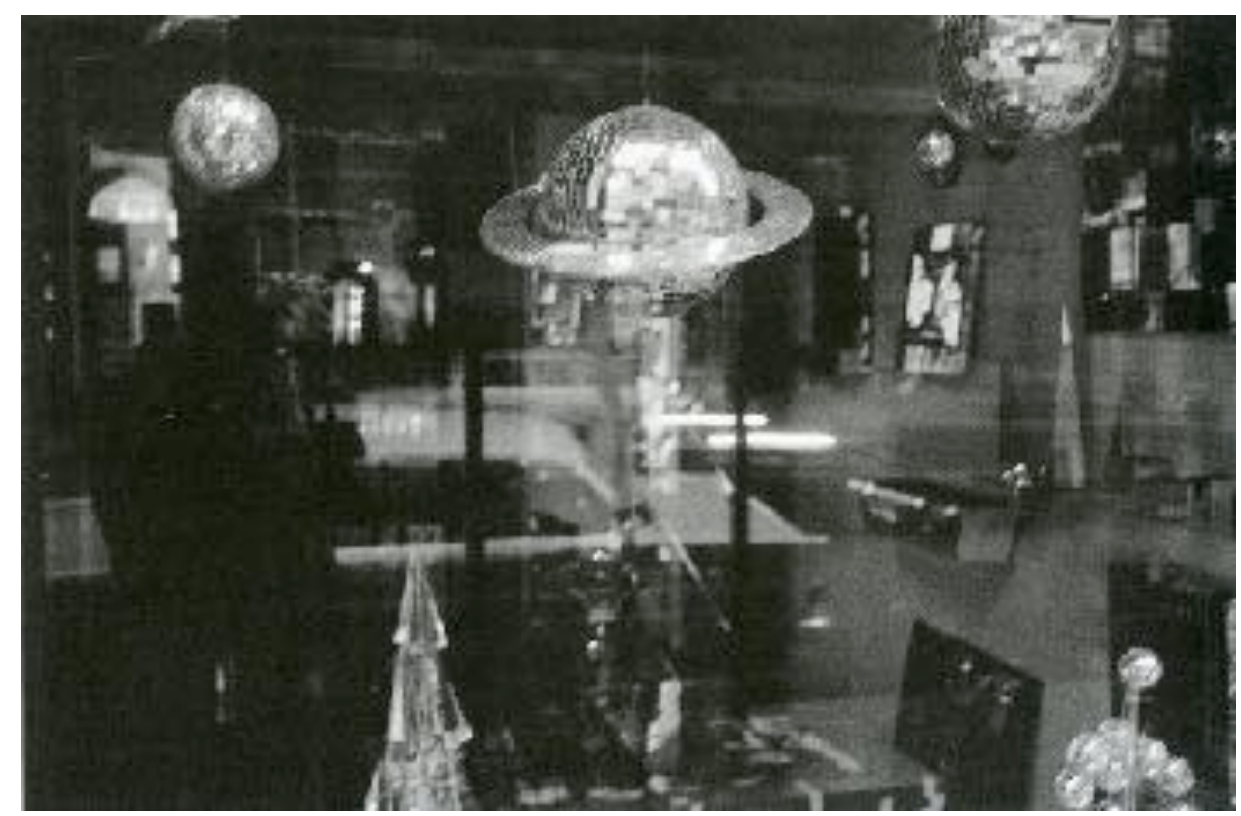

Fig. 14 


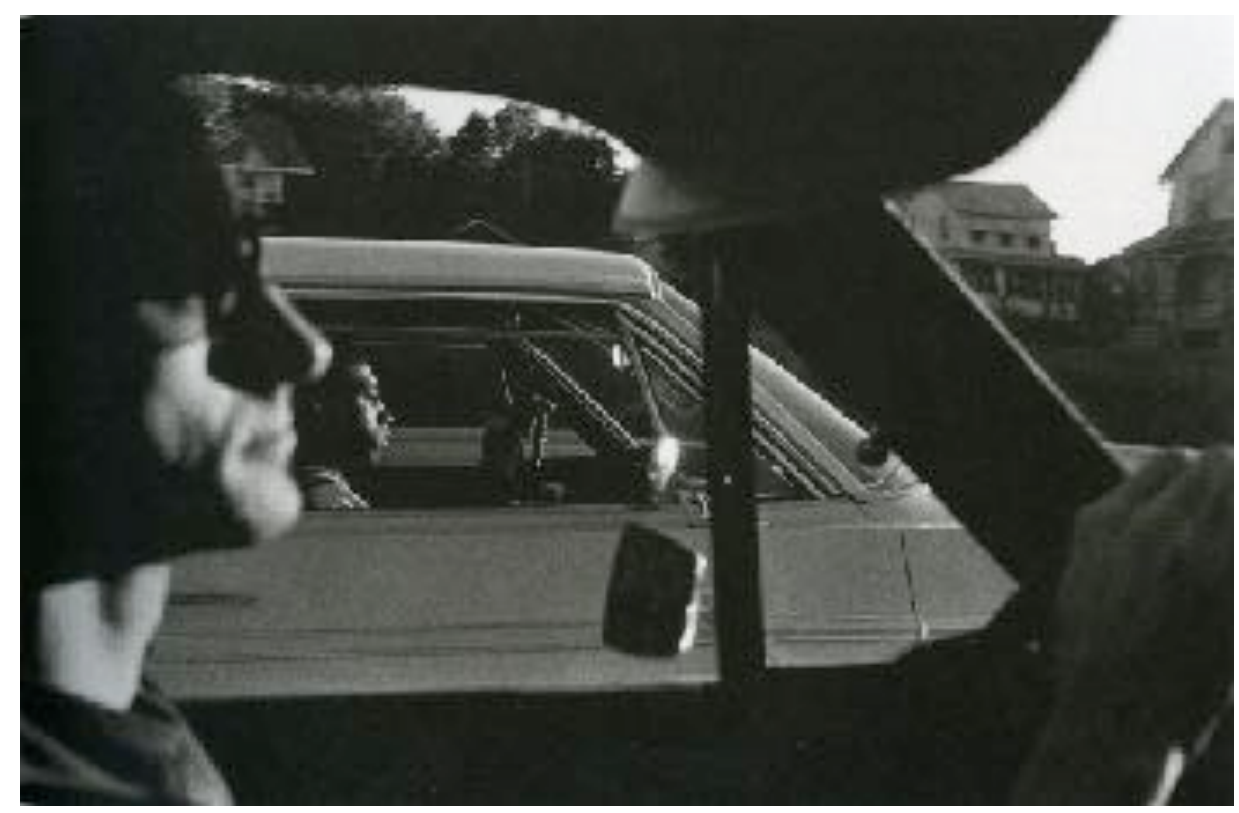

Fig. 15

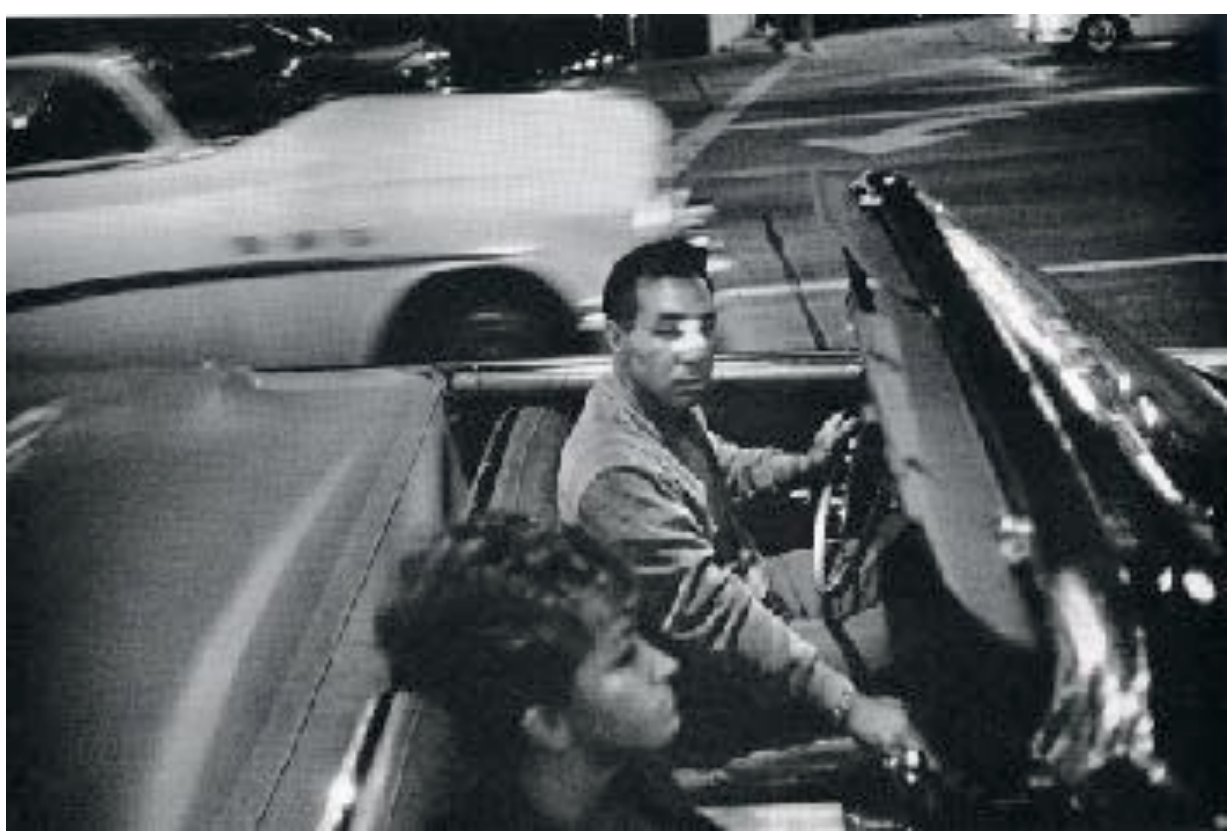

Fig. 16 
American photography on Gagnon's work is clear. In fact, he had relationships with many photographers across the border. In his 1979 interview with Katherine Tweedie, the Montreal photographer Sam Tata recounts an anecdote about taking Robert Frank's portrait and notes that the artist "was on a visit at Charles Gagnon's house."49

Throughout this period, Canadian photography was developing alongside its American neighbour and following a similar path. In 'A short history of photography, 1900-2000', art historian Martha Langford provides a summary of the developments of documentary photography in Canada. This approach to photography moved from official government capacities to the popular press as publications like Canadian Magazine established themselves as the sources to visual information in the 1920's and 1930's. ${ }^{50}$ The National Film Board of Canada (NFB) created its Stills Photography Division in 1941, which controlled much of the production of photo-essays for the Canadian press..$^{51}$ In the 1960 's, however, documentary photographers began to turn to more personal projects where they could express themselves rather than the editors' agenda. Langford refers to these photographs as 'Modernist Documents' ${ }^{52}$. There is a motivation to document reality whilst being deeply concerned with the aesthetic qualities of the image.

\footnotetext{
49 Tweedie. 114

${ }^{50}$ Langford. 279-311

51 Carol J. Payne, The Official Picture. 19

52 Langford. 279-311.
} 
While landscape was being re-defined across North America, it is important to note that Canadian art has a particular rich history with the genre. Landscape painting in the first half of the twentieth century had a major role in forming a national identity that the country has still not completely shed to this day. The legacy of the Group of Seven, the artists who were instrumental in forming this national idealism, is difficult to shake. Starting in the 1960's, however, there is an attempt to dismantle these traditions of the Northern landscape as the symbol of the Canadian nation. In their book Beyond Wilderness : The Group of Seven, Canadian Identity, and Contemporary Art, art historians John O'Brian and Peter White present a multitude of artists who were engaged in this re-imagination of the Canadian notion of landscape. They explain that “since the 1960's, artists have investigated social relationships within landscape as a way of moving beyond the legacy of the Group of Seven." 53 Gagnon is one of them. In both the Minox and SX-70 works, he photographs nature as it exists within human-made landscapes.

Charles Gagnon, while not necessarily concerned with issues of locality, mostly practiced in Québec but was also supported by the Canadian arts community at large. However, it is important to contextualize his work within the milieu of Québécois photography in the 1970's. Ryerson University organized in 1979 an exhibition and conference titled 'Canadian Perspectives,' where Gagnon's Minox photographs were exhibited as a stand-alone installation for the first time. In one portion of the conference, scholars spoke about the current status of contemporary photography in each of the major Canadian regions: the Maritimes, Québec, Ontario, the Prairies, and British Columbia. ${ }^{54}$ One cannot help but notice the exclusion of the

\footnotetext{
53 John O’Brian and Peter White. Beyond Wilderness. 4

54 Canadian Perspectives : Conference Transcript. Toronto. 93-192
} 
Canadian Territories in this list. Nevertheless, this kind of regionalism revealed a detailed insight into the contemporary photographic practices developing in different parts of the country at the time that Gagnon was producing the Minox and SX-70 work. In her presentation, photography scholar Katharine Tweedie categorizes the work being made in Québec into two general groups. First, she explains that there are photographers involved in creating social documentary work, where "there is certainly a desire for the photographs to serve a function - to illuminate social conditions, to give a public voice to those who do not have access to one." 55 The Montreal magazine $O V O$ was one of the main outlets for this kind of photography and published the photographic projects of artists like Gabot Szilasi and Pierre Gaudard who presented Québécois social culture. 56

In 1972, four photographers from Québec, Claire Beaugrand-Champagne, Michel Campeau, Roger Charboneau and Cedric Pearson began a photographic project that perfectly exemplifies the politically-driven social documentary tradition in Québécois photography. The group of photographers sojourned to Disraeli, a small town in the eastern townships of Québec, where they photographed inhabitants in their everyday environments. The result of this project was a photo-essay published in Perspectives, an image-based insert in the weekend edition of the Montreal newspaper La Presse (Fig.17) ${ }^{57}$. In Beaugrand-Champagne's Ti-noir LaJeunesse, one of the project's most iconic photographs, we can see the local violinist sitting on his property. It is clear from this image, that the photographers were deeply concerned with content but also

\footnotetext{
55 Tweedie. 110

56 Ibid. 111

57 Ibid. 112
} 
form. The contrast of the photograph has been enhanced to dramatize the portrait, which is already being made grandiose by the angle at which the subject is photographed. Here, Langford's term of 'Modernist Document' very much applies. Beaugrand-Champagne, Campeau and Charbonneau went on to form the Group d'Action Photographique (GAP) along with Szilasi and Gaudard, a group dedicated to making socially productive photographic work, as their name suggests. ${ }^{58}$

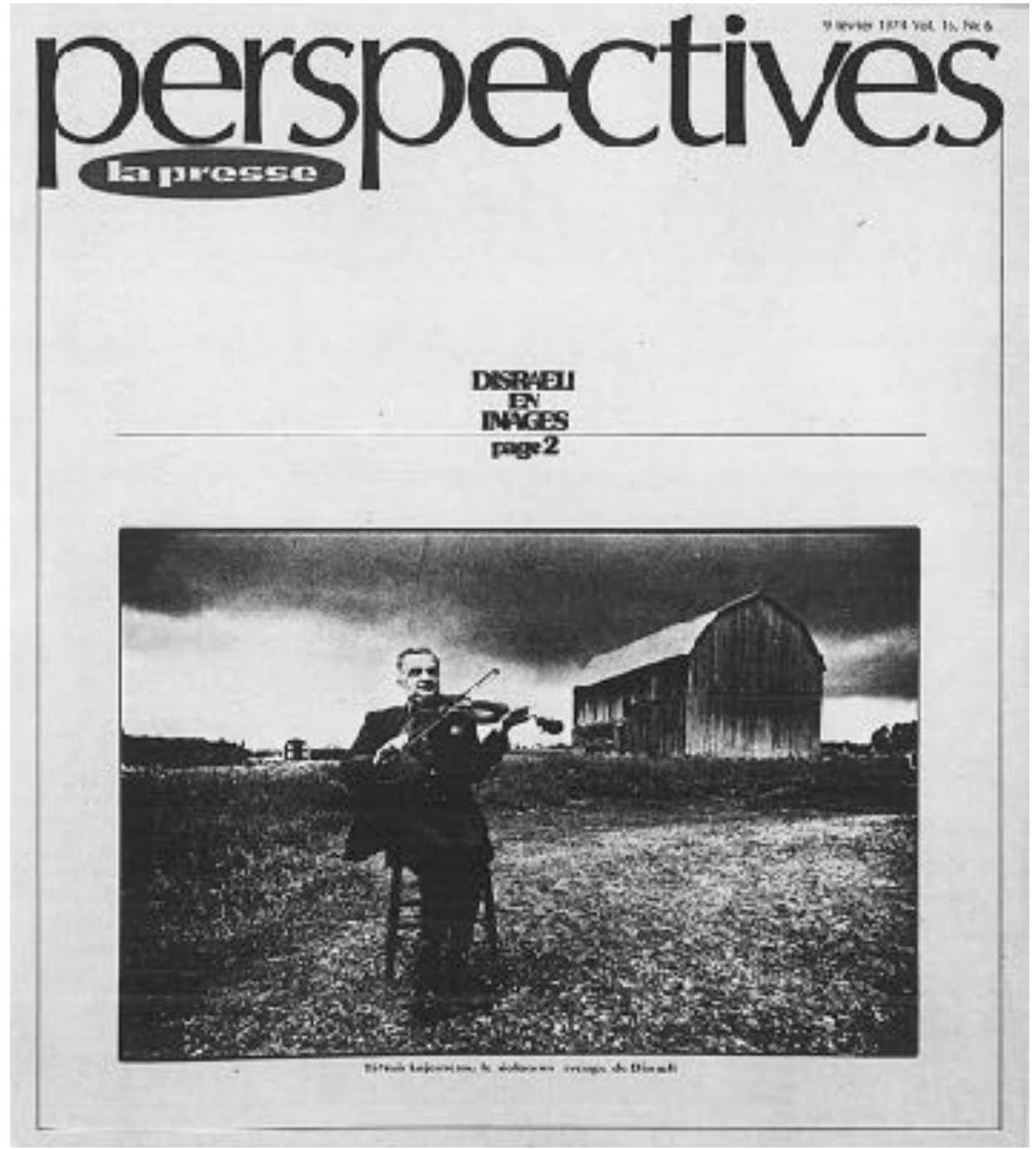

Fig. 17

58 Tweedie. 117 
The second trend in Quebec photography brought forth by Tweedie is the "use of the medium as a means of personal expression." 59 She places Gagnon's work in this category as she explains that he is "amazed by what goes on in everyday life and photograph(s) it." 60 Gagnon was not interested in photographing people the way that the GAP was. Rather, he explored objects' relationships to each other, bringing out some of the visual dynamics of the everyday, which might otherwise be missed. While his work was not overtly political like much of the documentary work being made in Montreal in the 1970 's, there seems to be a refusal to engage with Québécois rhetorics of identity as rooted in concepts like language and nation-hood. Perhaps this attitude contributed to Gagnon never being considered a true 'Montréal painter' like some of colleagues such as Yves Gaucher, with whom he shared a studio for years in Old Montreal. ${ }^{61}$

In the AGO's collection of Minox prints, the human figure is seldom represented and when it does appear, it is in movement, cut off by the frame of the image, somehow obscured, or as a mere shadow as we can see in $M N$ : XXVIII - 28 - 77. (Fig.18) However, these are no natures mortes, they are not lifeless, as nature is activated in its dialogue with the human-made. Much of the photographs' conversations, as Asselin describes them, occur between the natural and the artificial landscapes pictured. ${ }^{62}$ In $M N: X X V I I I-28-77$, the vegetation is growing next to a patch of concrete and in front of a wall of corrugated metal, striving in a non-nurturing environment. The natural, stubbornly survives in the urban environment, sometimes in almost

\footnotetext{
59 Tweedie. 110

${ }^{60}$ Ibid.

61 Thériault. 13

62 Asselin and Gagnon. 120
} 
absurd ways, throughout Gagnon's Minox photographs. This motif lines up quite well with his notion that everything, even a rock, is alive. ${ }^{63} \mathrm{He}$ does not establish a hierarchy between one and the other but rather observes the dynamics between the two that have naturally made themselves visually striking.

While the juxtapositions are more subtle in the Minox prints, they are at the very centre of the SX-70 works as all are photographs of an outdoor space taken from the confines of an indoor space. Gagnon makes the barrier between himself, or the viewer, and the natural space impossible to ignore by including the window frame in the foreground of each photograph. In many cases, in fact, the window frame makes up the majority of the image (Fig. 19), highlighting this distinction of the artificial and the natural. The linear shapes of the frame act as interjections, or interruptions of the natural landscape and its organic shapes. In these photographs, Gagnon creates the sense that the natural world is observable yet unaccessible to the photographer and the viewer. With this project, the artist creates a physical representation of his process as a photographer. These photographs are clear illustrations of Gagnon as an observer, who does not physically access the space he is photographing. This is peculiar as the Polaroid process is much more involved in the making of photographs rather than the mere taking of them, unlike the Minox process. These kinds of contradictions, however, add to the complexity of Gagnon's work. The photographs are never as straight forward as they seem. One must take time to appreciate the plurality of their meaning.

63 Tweedie. 119 


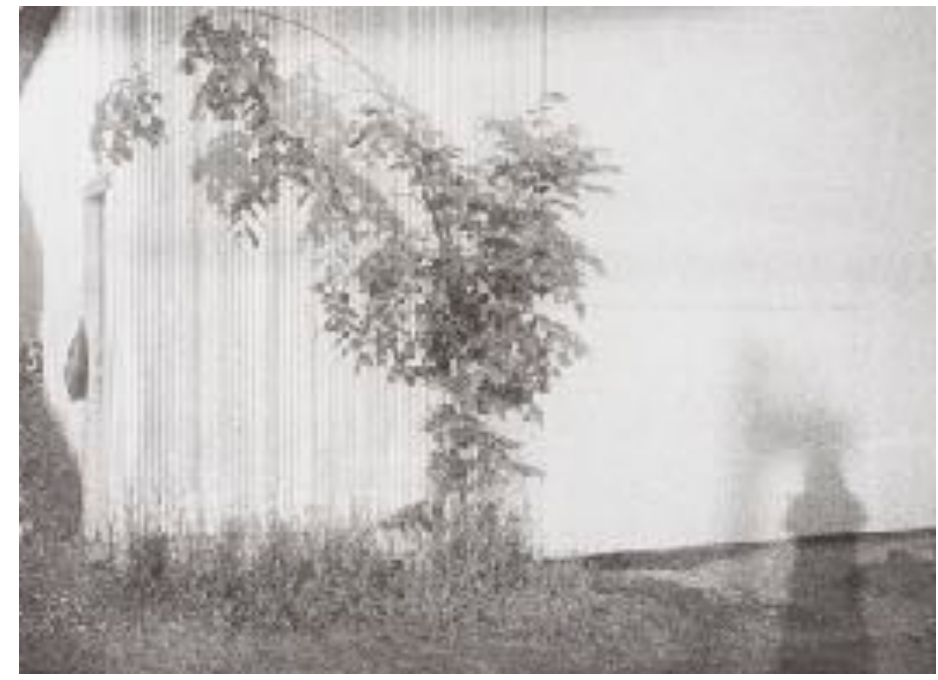

Fig. 18

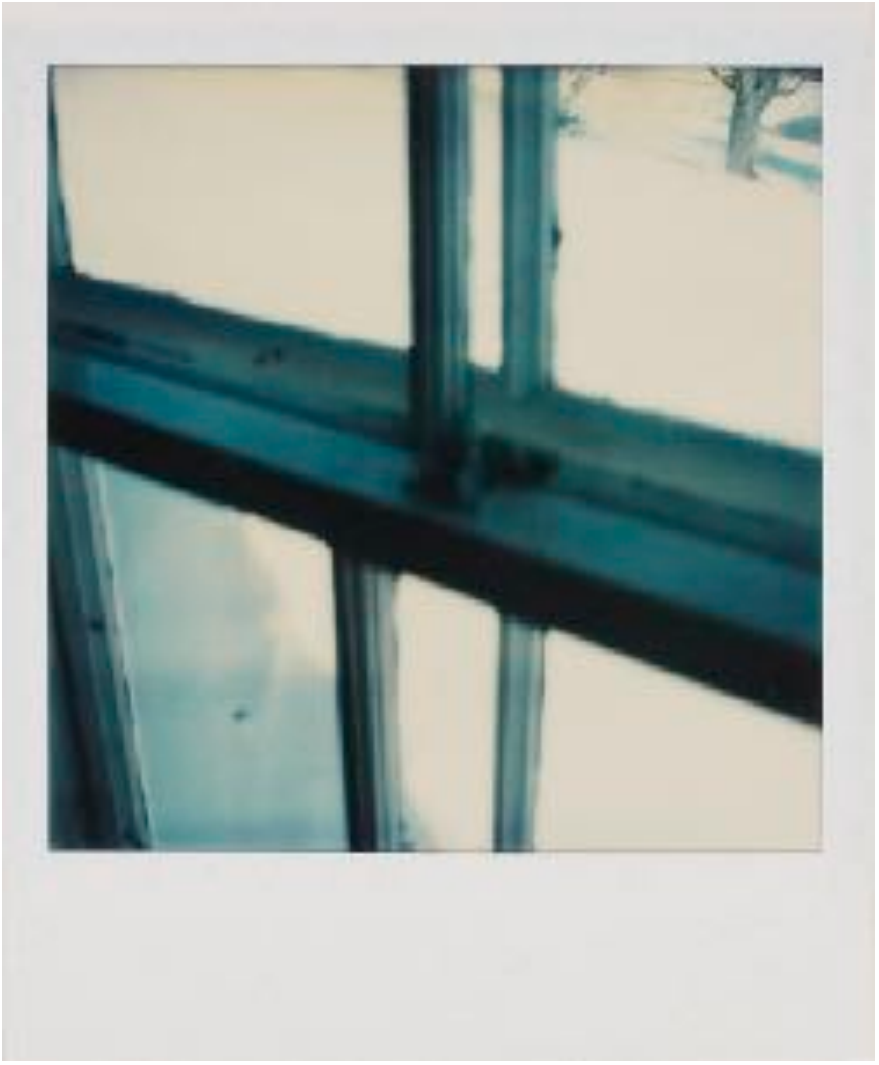

Fig. 19 


\section{Chapter IV : Windows: Creation of a Frame}

The theme of the window is present throughout Gagnon's artistic oeuvre and creates relationships between the multiple works in a number of ways. Most noticeably, it is a reoccurring visual component of the images, whether photographic, painterly or otherwise constructed. The artist often imposes upon himself the restriction of a frame within the frame of the canvas or viewfinder. The window also links the work on a more symbolic level. The idea of the transparent window aligns itself with the plurality of Gagnon's photographs and paintings. The dialogue between 'here' and 'there', 'in' and 'out', 'input and output', is materialized through the physical barrier of the window pane. It plays an important role in both the Minox and SX-70 photographs, not only as a visual marker but also as a methodology, a way in which to photograph the world.

When he was 17 years old, Gagnon broke his leg in a skiing accident. This resulted in a month of bed rest, during which he mostly read and looked out of his living room window. He has explained these moments of gazing towards the outside to be moments of deep reflection. From then began an infatuation with the idea of the window, which would later make its way into his artistic endeavours. 64

This interest becomes apparent early on in a series of sculptural works, where Gagnon places paintings inside wooden boxes and behind glass. These were produced between 1962 and 1968. In The Window (Box No.6) (Fig. 20), the artist makes the viewer peer through a pane of

64 Lamy and Gagnon. 12:43-13:15 
glass to look at the painting. This transparent barrier is clearly understood as a window because of the pull-down blind and moulding included in the sculpture. He takes his experience of looking out the window and turns it around, making us look in from the outside. In a way, the glass gives the painting a precious quality, it must be protected. The viewer is separated from the materiality of the paint, it must be observed without being touched. This work creates a clear dichotomy between the concepts of the in and the out. This dichotomy is in part what interests Gagnon the most about the window, it provides a visibility onto the world, while simultaneously preventing physical access to it. The feeling of observing the world whilst being detached from it is very much present in the practice of photography, where the viewfinder provides a barrier not unlike Gagnon's living room window, out of which he stared as a teenager.

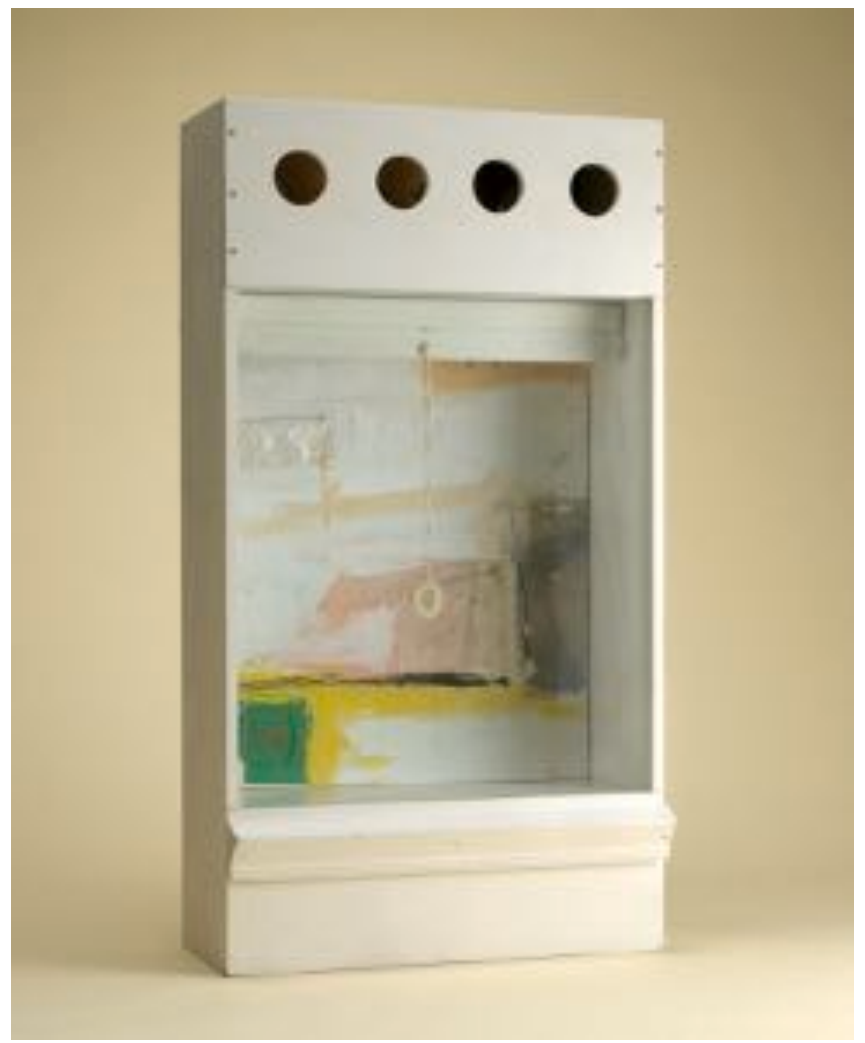

Fig. 20 
Gagnon is not the first artist to find an interest in the idea of the window. It has in fact been used as a visual motif for centuries. The artist looking out onto the world from the studio's window is a familiar image. French impressionist Claude Monet painted the cathedral of Rouen in Normandy over and over again from a window across the street between 1892 and 1893. Similar impulses appear in the history of photography. Works in the AGO's collection illustrate this popular interest. Much like Gagnon's SX-70 works, Josef Sudek’s series 'The Window of my Studio' represents the outside world from an interior standpoint. We can see in From My Window (Fig. 21) that the window pane and its changes in texture and opacity are just as much part of the composition as the objects on the other side of the glass. The mediation of the window on the artist's vision of the outside world is in the forefront of this photograph, in the way that the tree is blurred, almost abstracted.

Perhaps, photographers are attracted to the window for its similarity to the viewfinder, a physical barrier between the artist and the subject, which still allows visibility. In the case of Gagnon's Minox and SX-70 photographs, however, this visibility is very much affected by the apparatuses' particular viewfinders, mediating his vision much like the permutations on Sudek's window. It is not only as the viewfinder, but also as the subject of the photographs, that the window makes its way into Gagnon's work. In many cases, the Minox images were created looking in or out of a window. Often, this window is the one of a car like in $M N: X X X V I-23-77$ (Fig. 22). In this photograph, the woman walking on the street is distanced from the viewer through several layers of transparency, the windshield of the car as well as the plastic panels of her umbrella. While there are three persons represented in this photograph, Gagnon seems more 


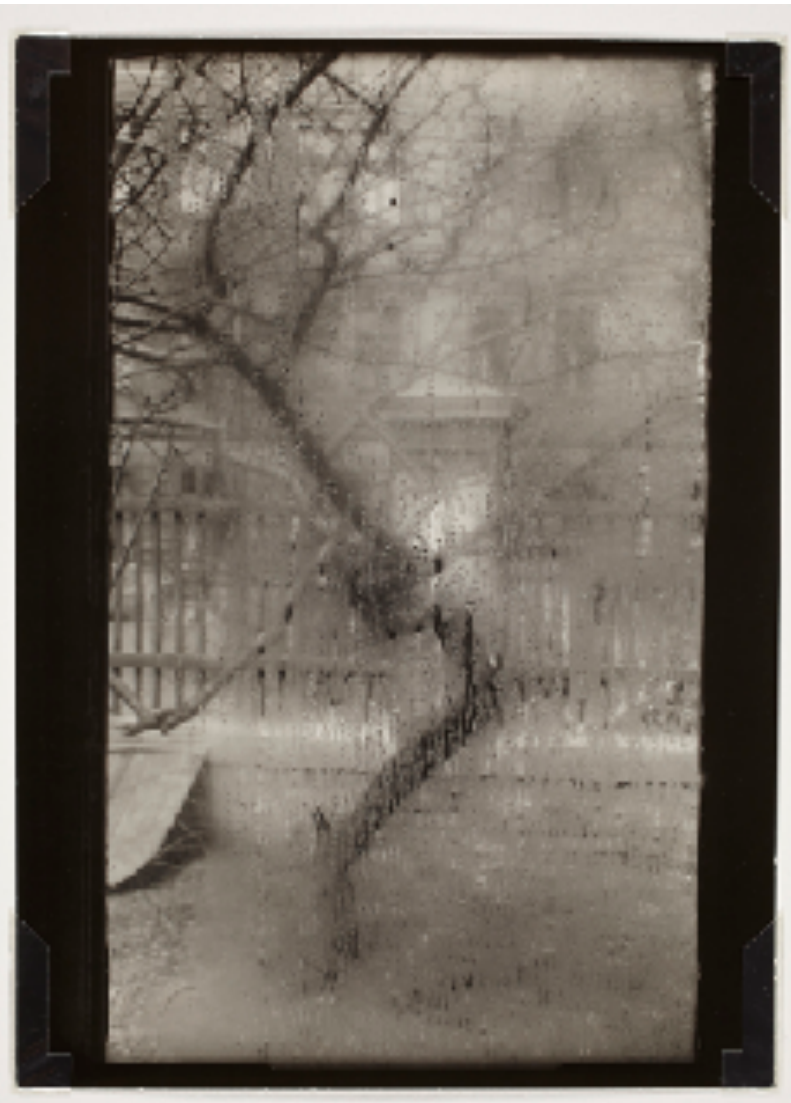

Fig. 21

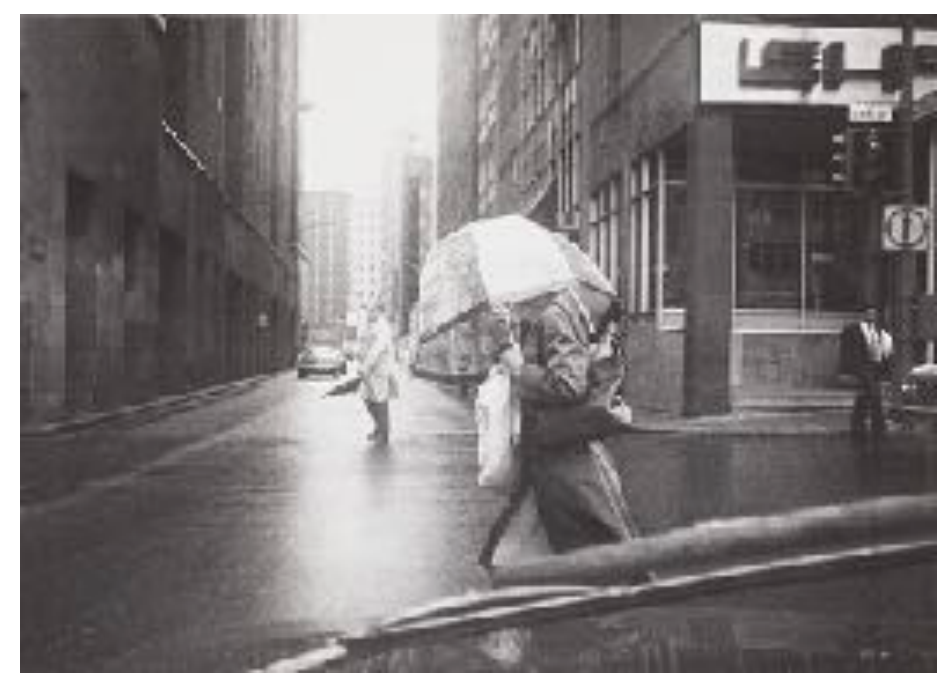

Fig. 22 


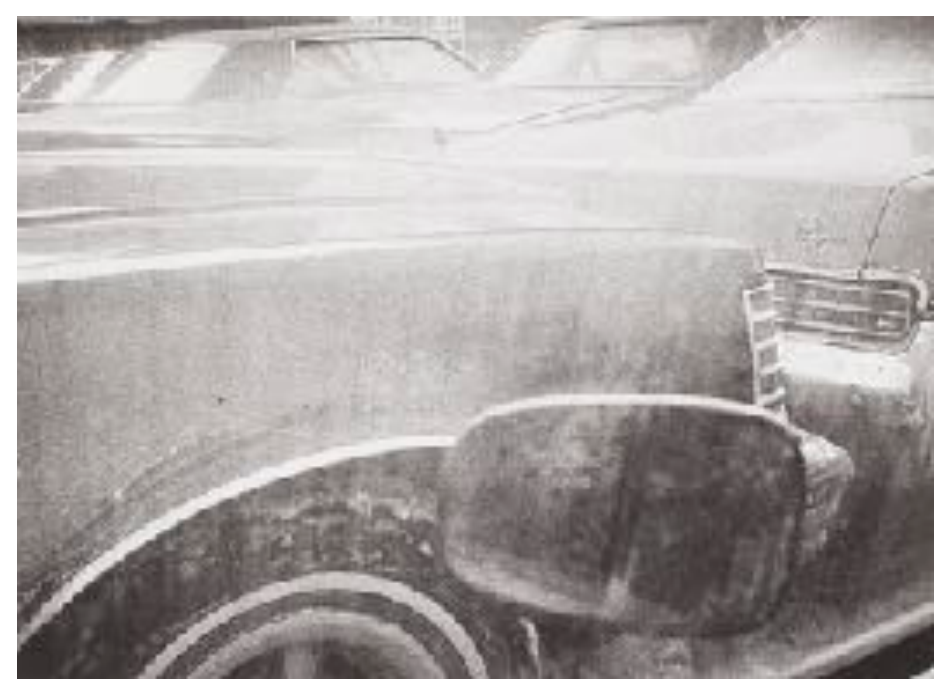

Fig. 23

interested in them as forms rather than human beings. The texture of the woman's raincoat plays a larger role than she does in the composition of the image. In fact, her face is completely obscured. The window positions Gagnon as an observer, the role he embodies when photographing. This gives him the distance needed to notice aspects of the world without the attachment of being physically involved in them. The inclusion of both windows and mirrors throughout the Minox photographs can also be linked to Gagnon's optical interest in the camera itself. He experiments with transparency and reflective surfaces in most of the work. A clear example of this is $M N: X L V I I-11-78$ (Fig. 23), in which the frame is filled with car windows, hoods and mirrors. Photographs like this one were made at a time where reflection was also playing an important role in Gagnon's painting practice. In works like Étapes \#2 (Fig. 24), light hitting the canvas allows the viewer to see the brushstrokes within the solid blocks of colour. The texture of these brushstrokes, made visible through the reflection of light, is a crucial aspect of many of Gagnon's painting throughout the 1960's and 1970's. 


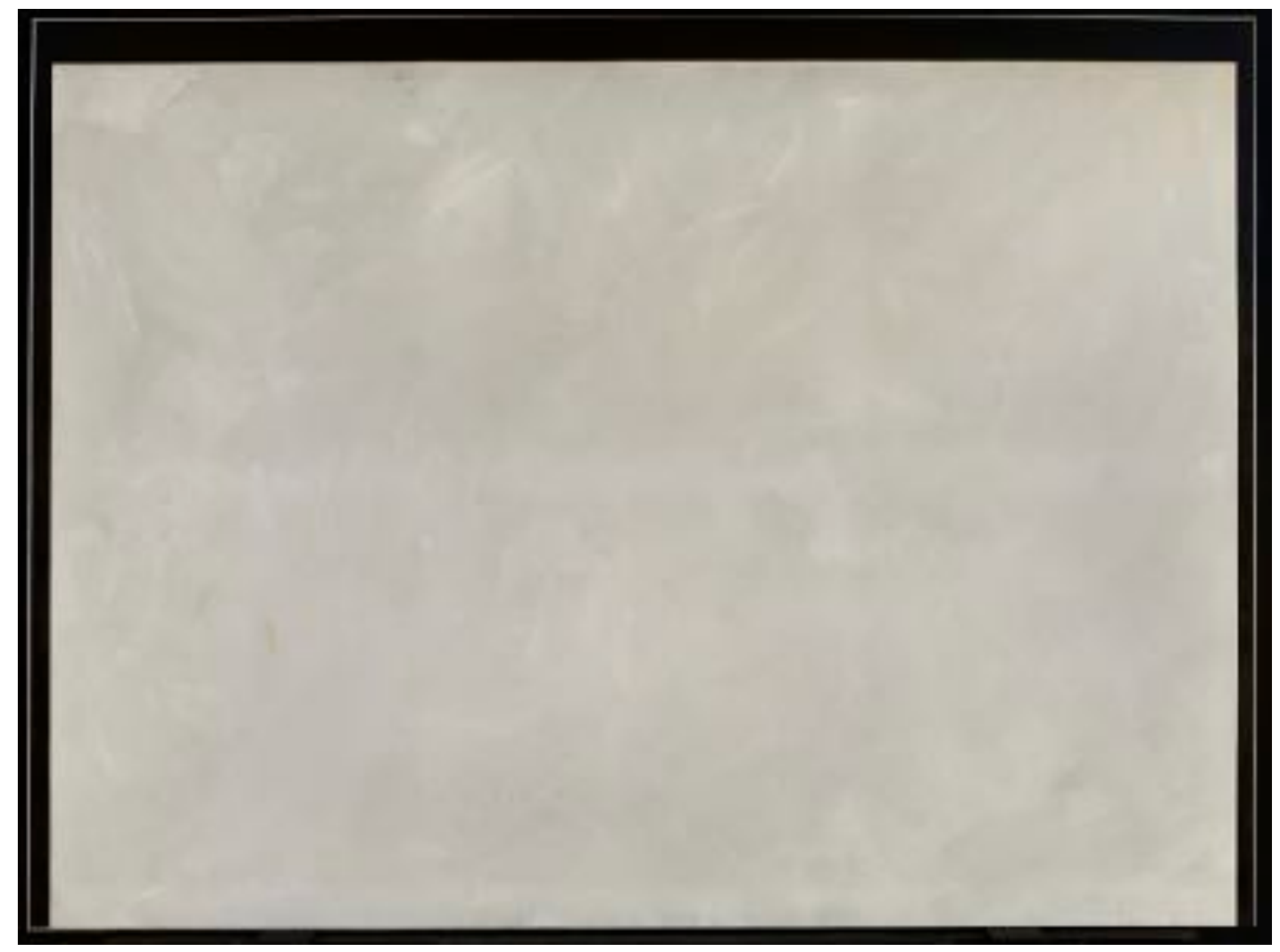

Fig. 24

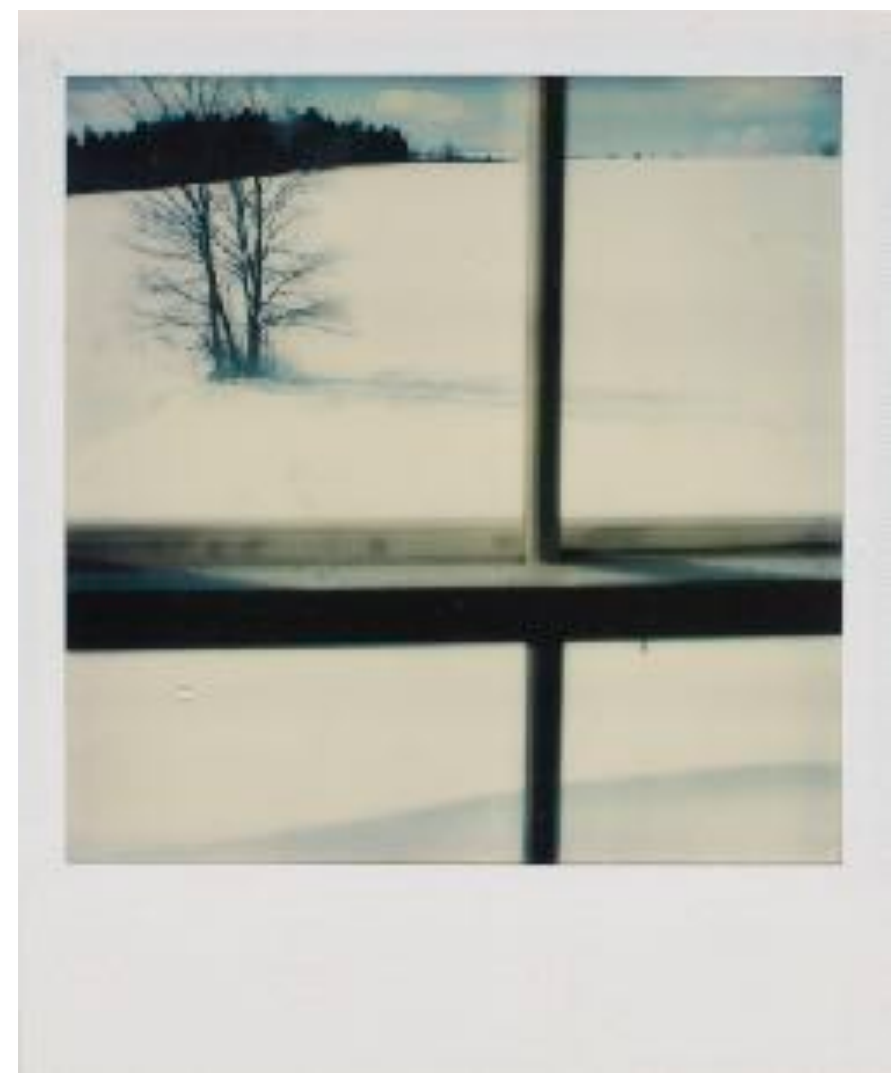

Fig. 25 
Étapes \#2 is also a useful example in comparing the use of a frame within a frame in Gagnon's SX-70 and painting compositions. In the Polaroid prints, the window frame in the foreground of the image is often used to accentuate aspects of the background. In $S X-70(65 / 100)$ (Fig. 25), a tree is perfectly positioned within one of the window squares. Gagnon very similarly applies additional orderly restrictions to the image plane of his paintings. In Étapes \#2 there is a border around the edge of the canvas, which demarcates two distinct areas in which to paint.This border is reminiscent of the one around a Polaroid photograph. In the SX-70 work, Gagnon is working within an additional frame because of the inherent form of the photographic film he is using. The Polaroid prints themselves resemble windows, the protecting layer of plastic acting like glass between the viewer and the image, allowing us visibility but not contact. There are several examples of Gagnon's paintings resembling aspects of the photographic apparatus. In Continuum (Fig. 26), the canvas is separated into strips that remind us of film negatives arranged

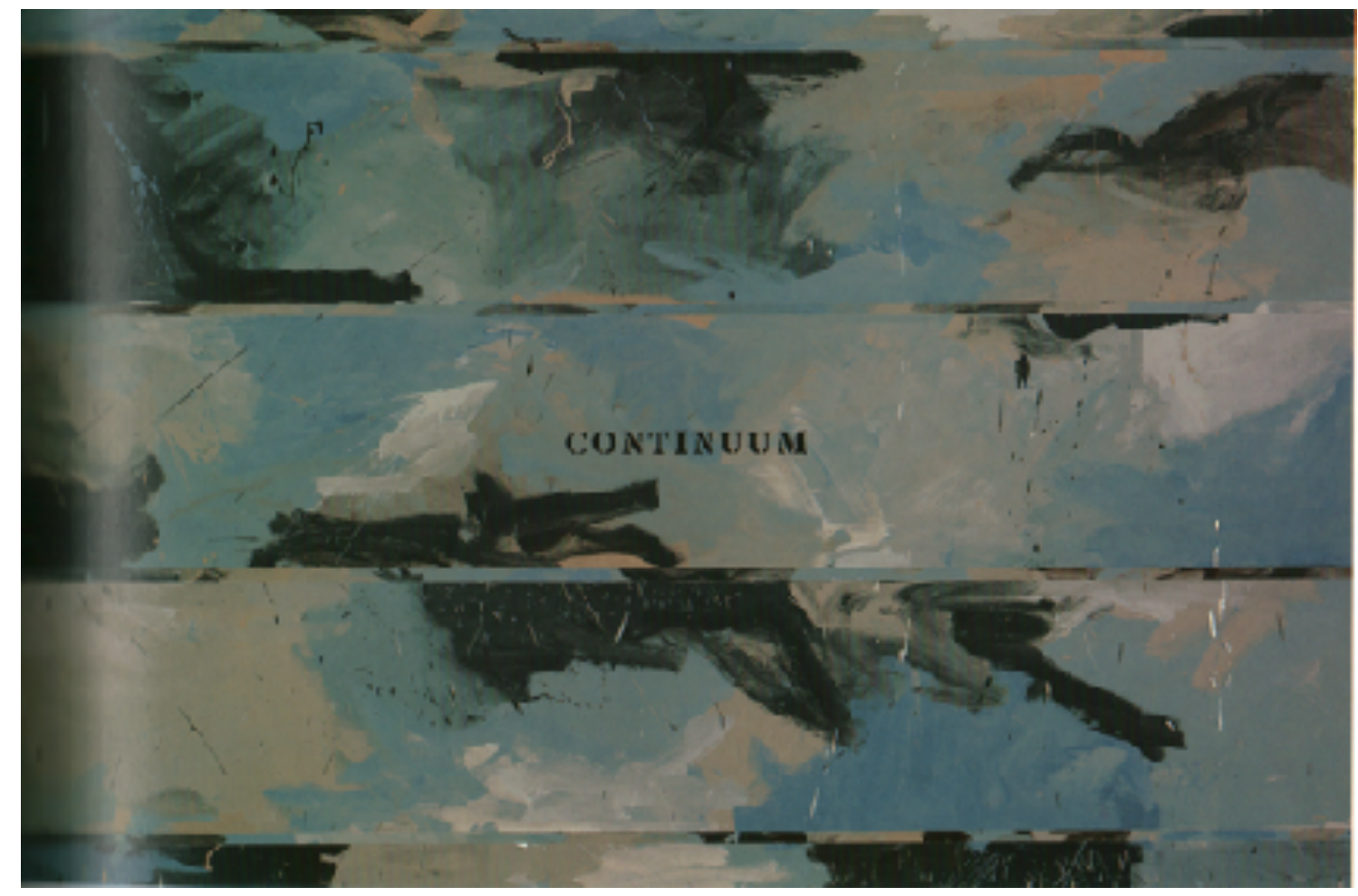

Fig. 26 
to create a contact sheet. Again, we see references to different disciplines within the work. While the materials remain separate, Gagnon creates a conversation between his multiple mediums throughout his oeuvre.

In the SX-70 photographs, the window takes on a role similar to the viewfinder in the camera. While making these works, Gagnon is not only metaphorically, but also physically separated from the subject. The window creates a barrier between the inside and the outside, the natural and the human-made, the artist and the subject, the input of light and the output of the Polaroid print. These opposing concepts are separated but also in conversation, much like the inanimate objects in Gagnon's black and white photographs are in conversation, and much like all his mediums form a dialogue. In her book Faking Death, Cousineau-Levine argues that this separation represents the feeling of being an outsider, which is symbolic to the Canadian identity. ${ }^{65}$ Gagnon, however, was never interested in making specifically Canadian art. He believed in the international and universal nature of art, which is in fact conditioned by a kind of universal conversation between the inside and the outside in the SX-70 photographs. The transparency of the window is at the root of Gagnon's fascination with the object, it allows a fluid passage of light while maintaining a certain balance between what is in and what is out. When speaking to Lamy in 1979 about this harmony he finds in the world, Gagnon mentions the concept of Yin and Yang, a reference to some of the Eastern philosophy he encountered and sustained throughout his artistic career. Much of the Minox work also seems to be founded around the balance between opposing forces, a tug and pull between Gagnon and his subject, oftentimes created by the appearance of the window as a mediating pane between the two.

65 Cousineau-Levine. 90 
The window appears as a common trope throughout Gagnon's photographic work. It is difficult to find an image without some kind of glass pane in the entirety of the $35 \mathrm{~mm}$ works exhibited in the Observations retrospective. However, it is in the Minox and SX-70 photographs that the concept of the window comes alive as its form takes a more prominent place symbolically within the compositions. The function of the window in these two groups of works creates a structural connection with Gagnon's painting practice but also a philosophical alignment with his multi-disciplinary approach to art-making. 


\section{Conclusion}

As one of the country's foremost multi-disciplinary artists, Charles Gagnon's oeuvre is incredibly important to the history of Canadian art. The plurality of his various modes of production, which range from painting to photography, film and design, as well his interest in ancient cultures and philosophy are connected through his open-ended approach to art making. His practice is driven by philosophical concepts based on harmony and balance, and the rejections of ideas such as the "myth of inanimate objects," and the locality of art. ${ }^{66}$ Many of these points of view come from Gagnon's interest in Zen Buddhism, transcendental and metaphysical thought. His philosophy, about life and about art, is complex to grasp as it is highly cerebral and relies on the idea of ambiguity. These personal associations are deeply connected to the multi-disciplinary nature of his work and emerge throughout the oeuvre. They are particularly apparent in two groups of photographs, which mark an innovative period of his career. Between 1976 and 1979 he experimented with two new types of camseras, the SX-70 type Polaroid and the sub-miniature Minox. This moment is particularly poignant to the relationship his photography has with the rest of his oeuvre. The characteristics of these two apparatuses are visible in the images they produce. They illustrate Gagnon's philosophical impulses as an artist, in which ambiguous and enigmatic qualities are significant. ${ }^{67}$

Two photographs encapsulate the different aspects of the Minox and SX-70 work that makes it so telling of the position photography has within Gagnon's artistic practice. The works are connected to Gagnon's philosophy in their engagement with the notions of 'Input' and

\footnotetext{
66 Asselin and Gagnon. 118

67 Lamy and Gagnon. 15:24-15:31
} 


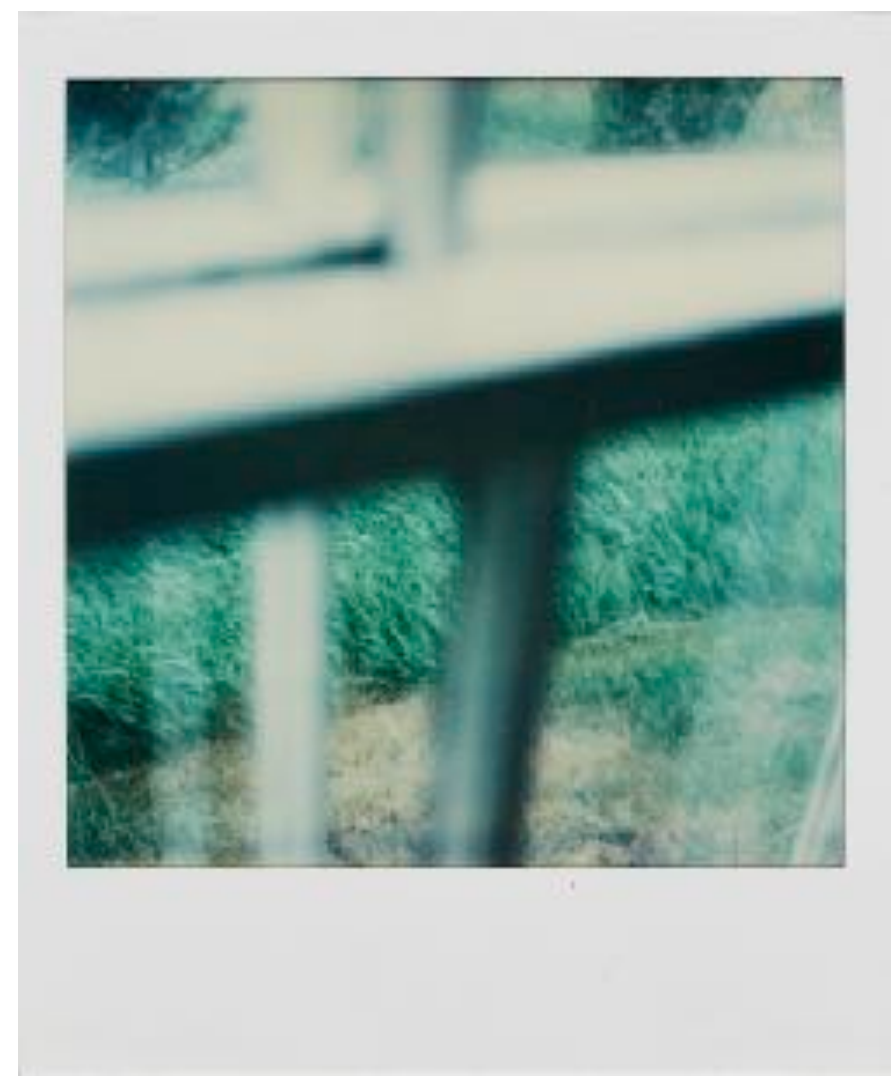

Fig. 27

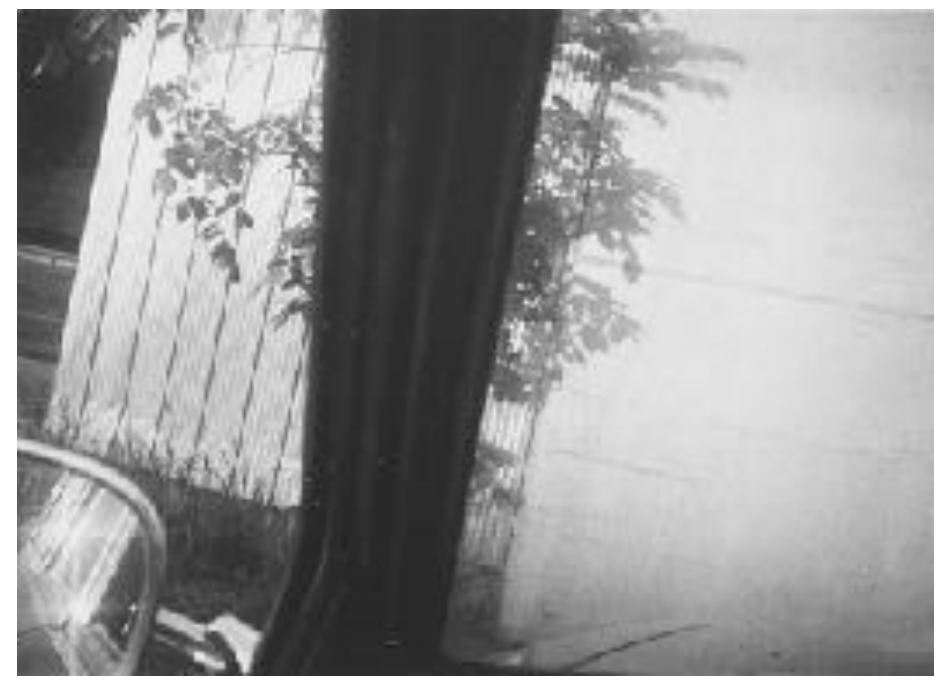

Fig. 28 
'Output', their treatment of the landscape genre, and the window as a reoccurring visual motif. In $S X-70$ (78/375) (Fig. 27), the blurry window frame takes up much of the space in the photograph. Because the SX-70 was the first Polaroid SLR, Gagnon was able to clearly focus on the lawn outside of the window. The frame acts as an interruption to the natural landscape's visibility. Similarly, the dark car frame in $M N: X X X I I I-2-77$ (Fig. 28) interrupts the view of the outside as it intersects with the form of a tree. The mediation of the window is made apparent in both photographs by the presence of the frame. There is a conversation between the inside and the outside space, one that is also grounded in the interaction of the human-made with the natural. There is a balance between the two in these photographs, a yin and a yang. These concepts run parallel to his notions of 'input" and 'output', which he has used to convey his photographic role as an observer rather than a maker of images.

Gagnon's philosophy about the harmony between objects emerges as they are activated in his work. This activation is emphasized by the tilt of these two compositions, giving the photographs a sense of movement in line with the spontaneous fashion in which these two apparatuses are used. This spontaneity comes from the Minox's portability and the SX-70's instantaneous quality. The reflection of the window frame can be seen in $S X-70$ (78/375), while reflections appear both in the car's sideview mirror and on its hood in $M N: X X X I I I-2-77$. These optical features intrigued Gagnon as he played with transparency and reflection in his photography and his painting throughout the 1960's and 1970's. The traces of the apparatuses used to make these photographs are not only present in the images' subject matter, but also in the overt materiality of the prints. As the first fully integral instant photograph, the SX-70 print feels like an entire object rather than an image printed on a paper support. Their materiality and colour 
bring the Polaroid photographs close to Gagnon's painting. The form of $S X-70(78 / 375)$

resembles its subject matter: a window. The Minox produces very small negatives, lowering the amount of silver grain within the frame. This results in a grainier image once it is enlarged.

$M N$ : XXXIII-2-77 is a much less fine and sharp image than Gagnon's prints made from $35 \mathrm{~mm}$ negatives. The materials used to create the photograph are not hidden, the evidence of the smaller negative is in fact embraced and in the forefront of the image. The visibility of these photographs' materiality allows us an insight into the way they were produced and, as a result, the ways in which Gagnon expressed his philosophical view points through photography.

The Minox and SX-70 photographs represent a very small portion of Gagnon's photographic work. They were only produced for a very short amount of time, in the middle of a career dominated by the production of painting and more traditional $35 \mathrm{~mm}$ black and white photography. This moment is an anomaly within the artist's oeuvre, and often anomalies can be quite revealing. In this case, these works made during a tumultuous decade for the production, presentation and status of photography, give us insight into the multi-disciplinary artist's approach to art, which without a doubt is also a product of its time. He learned from American photographers of the 'social landscape' and Québécois 'social documentarians' but re-defined the urban landscape on his own terms. His juxtaposition of natural with artificial objects and his use of fleeting human figures abstract the cityscapes into a state of ambiguity. This and the way these photographs were produced is directly related to the characteristics of the Minox and the SX-70 cameras. Gagnon's photography has been considered separate from the rest of his work, yet the use of these two cameras has created a close relationship within the oeuvre that is deeply connected to Gagnon's philosophy about art and about life. Only a small portion of these 
photographs are in the AGO's collection, therefore there is much more to be learned about Gagnon from the rest of his Minox and SX-70 prints. There is little doubt that these works require further recognition as important parts of the long and significant career of a great Canadian artist. 


\section{Bibliography}

Arnold, Grant, and Karen A. Henry. Traffic : Conceptual Art in Canada, 1965-1980. Vancouver : Vancouver Art Gallery, 2011.

Asselin, Olivier. "Le Flâneur et l'Allégorie : Fragments sur les Photographies de Charles Gagnon." The Journal of Canadian Art History 20, no.1 (1999) : $182-203$

Asselin, Olivier, Charles Gagnon and Louis Goyette. Charles Gagon : du 8 Février au 29 Avril. ed. Godmer, Gilles. Montréal : Musée d'Art Contemporain de Montréal, 2011. Exhibition Catalogue.

Bonanos, Christopher. Instant: The Story of Polaroid. New York: Princeton Architectural Press, 2012.

Bradley, Jessica, and Lesley Johnstone. Sightlines: Reading Contemporary Canadian Art. Montréal : Artexte, 1994.

Buse, Peter. The Camera Does the Rest : how Polaroid changed photography. Chicago: University of Chicago Press, 2016.

Canadian Cultural Poesis: Essays on Canadian Culture. ed. Sherbert, Garry H., Annie Gérin, and Shelia Petty. Waterloo : Wilfrid Laurier University Press, 2006.

Cooper, Joseph D. The Minox Manual. New York: Universal Photo Books, 1961.

Cousineau-Levine, Penny. Faking Death: Canadian Art Photography and the Canadian Imagination. Montréal: McGill-Queen's University Press, 2014.

Cousineau-Levine, Penny, Olivier Asselin and Charles Gagnon. Charles Gagnon : Obervations. Québec : Musée du Québec, 1998. Exhibition Catalogue.

Cousineau-Levine, Penny, Lorne Falk, and Hubert Hohn. The Banff Purchase: An Exhibition of Photography in Canada (Banff Centre). Toronto: J. Wiley, 1979. Exhibition Catalogue.

Couture, Francine. Les Arts Visuels au Québec Dans les Années Soixante : La Reconnaissance de la Modernité. Montréal: VLB Éditeurs, 1993.

Fry, Phillip. "Foundations" in Charles Gagnon: Une Exposition Organisée par le Musée des Beaux-Arts de Montréal, 23-118. Montréal : MBAM, 1978. Exhibition Catalogue. 
Greenberg, Clement. "Modernist Painting." Art Yearbook4 (1961).

Heyer, Paul. Camerart : 24 Artistes du Québec. Montréal : Galerie Optica, 1974. Exhibiton Catalogue.

James, Geoffrey and Grant Arnold, “On the Work of Charles Gagnon." Lecture, Vancouver Art Gallery, Vancouver, BC, April 2013

Jasmin, Claude. "Deux Bonnes Raisons d’Aller au Musée." La Presse, November 17, 1962.

Kasemeier, Rolf. Small Minox, Big Pictures. Seebruck, Germany: Heering, 1966.

Krauss, Rosalind. "Notes on the Index: Seventies Art in America." October 3 (1977): 68-81.

Lamy, Laurent. "Charles Gagnon Et Le Culte de L'Ambigüité." Vie des Arts 23, no. 94 (Spring 1979): 40-44.

Lamy, Laurent and Charles Gagnon, "Charles Gagnon." L'Art Aujourd'hui, Radio-Canada, Montréal, QC, April 8, 1969.

Langford, Martha. "A Short History of Photography in Canada, 1900-2000," in The Visual Arts in Canada: The Twentieth Century, ed. Brian Foss, Sandra Paikowsky, and Anne Whitelaw (Don Mills: Oxford University Press, 2010), 279-311.

Leclerc, Denise. The 60's in Canada. Ottawa: National Gallery of Canada, 2005.

Lombino, Mary-Kay. "Instant Photography : The Allure and the Legacy." In The Polaroid Years : Instant Photography and Experimentation, 3-20. Poughkeepsie, NY: Frances Lehman Loeb Art Center, 2013.

Lyons, Nathan. Towards a Social Landscape. New York: Horizon Press, George Eastman House, 1966.

Marchand, Sandra. Esthétiques Actuelles de la Photography au Québec : Onze Photographes. Montréal : Musée d'Art Contemporain, 1982. Exhibition Catalogue.

Monk, Lorraine. Photography Canada 1967. Ottawa : National Film Board of Canada, 1968. Exhibition Catalogue. 
Mutely, Catherine. "Rétrospective Charles Gagnon: Les Paysages Invisibles." Vie des Arts 44, no. 181 (Winter 2001): 25-27.

Nasgaard, Roald. "Visit with Charles Gagnon." Canadian Art 18, no. 1, (2001): 60-66.

Null, Linda, and Julia Lobur. The Essentials of Computer Organization and Architecture. Burlington, MA: Jones \& Bartlett Learning, 2006.

O'Brian, John and Peter White. Beyond Wilderness: The Group of Seven, Canadian Identity, and Contemporary Art. Montréal: McGill-Queen's University Press, 2014.

Schaefer, John P. The Ansel Adams Guide: Basic Techniques of Photography - Book 1. Bulfinch, 1999.

Szarkowski, John. Mirrors and Windows: American Photography since 1960. New York: Museum of Modern Art, 1978.

Szarkowski, John. The Photographer's Eye. New York: Museum of Modern Art, 1966.

Scott, Kitty. Charles Gagnon: Recent Work. Edmonton: Edmonton Art Gallery, 1993. Exhibition Catalogue.

Statzer, Mary K. “'Photography into Sculpture' : Peter Bunnell, Robert Heinecken and Experimental Forms of Photography Circa 1970" PhD diss., University of Arizona, 2015.

Thériault, Normand. "Charles Gagnon." Vie des Arts, no. 53 (Winter 1969): 28-33.

Thériault, Normand. Introduction to Charles Gagnon: Une Exposition Organisée par le Musée des Beaux-Arts de Montréal, 8-19. Montréal : MBAM, 1978. Exhibition Catalogue.

Toupin, Gilles. “1978 : Une Année Amériquaine” La Presse, December 30, 1978.

Toupin, Gilles. "Camerart : pour faire le point" La Presse, December 21, 1974.

Toupin, Gilles. "Charles Gagnon : Des Fenêtres Sur L'Ambigu." La Presse, October 21, 1978.

Toupin, Gilles. "Une Photographie En Train de s’Affirmer." La Presse, July 31, 1976.

Toupin, Gilles. "Yajima et Optica." La Presse, July 7, 1979. 
Tousignant, Serge and Pierre Dessureault. Parcours Photographiques / Phases in Photography. Ottawa : Canadian Museum of Contemporary Photography, 1992. Exhibition Catalogue.

Tweedie, Katherine. "Photography in Québec" in Canadian Perspectives : Conference Transcript. Toronto : Ryerson University, 1979.

Vassar College. The Polaroid Years : Instant Photography and Experimentation. Munich : DelMOnico Books, 2013.

Vlas, Adelina, and Michael Snow. Michael Snow: Photo-Centric. Philadelphia : Philadelphia Museum of Art, 2014. Exhibition Catalogue.

Witkovsky, Matthew S. and Mark Godfrey. Light Years: Conceptual Art and the Photograph, 1964-1977. Chicago: Art Institute of Chicago, 2012. 